\title{
Estimation of Blade and Tower Properties for the Gearbox Research Collaborative Wind Turbine
}

Technical Report NREL/TP-500-42250

November 2007
G.S. Bir
F. Oyague

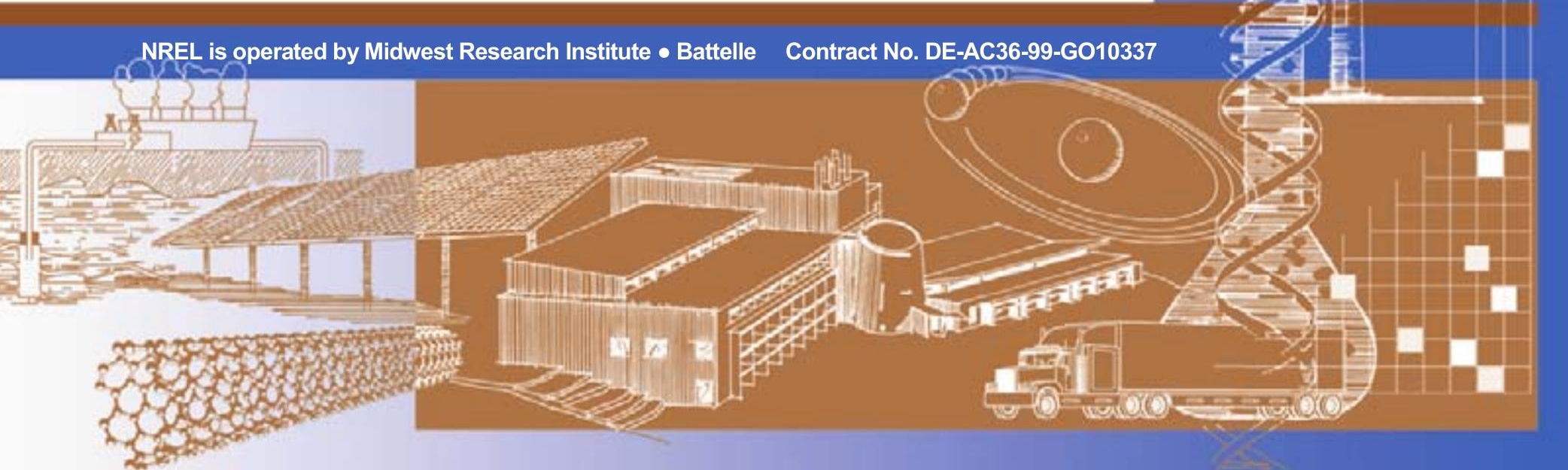




\section{Estimation of Blade and Tower Properties for the Gearbox Research Collaborative Wind Turbine}

Technical Report NREL/TP-500-42250

November 2007

\author{
G.S. Bir \\ F. Oyague
}

Prepared under Task No. WER8.2001

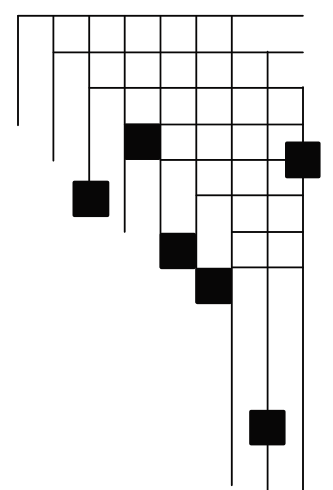




\section{NOTICE}

This report was prepared as an account of work sponsored by an agency of the United States government. Neither the United States government nor any agency thereof, nor any of their employees, makes any warranty, express or implied, or assumes any legal liability or responsibility for the accuracy, completeness, or usefulness of any information, apparatus, product, or process disclosed, or represents that its use would not infringe privately owned rights. Reference herein to any specific commercial product, process, or service by trade name, trademark, manufacturer, or otherwise does not necessarily constitute or imply its endorsement, recommendation, or favoring by the United States government or any agency thereof. The views and opinions of authors expressed herein do not necessarily state or reflect those of the United States government or any agency thereof.

Available electronically at http://www.osti.gov/bridge

Available for a processing fee to U.S. Department of Energy and its contractors, in paper, from:

U.S. Department of Energy

Office of Scientific and Technical Information

P.O. Box 62

Oak Ridge, TN 37831-0062

phone: 865.576 .8401

fax: 865.576 .5728

email: mailto:reports@adonis.osti.gov

Available for sale to the public, in paper, from:

U.S. Department of Commerce

National Technical Information Service

5285 Port Royal Road

Springfield, VA 22161

phone: 800.553.6847

fax: 703.605.6900

email: orders@ntis.fedworld.gov

online ordering: http://www.ntis.gov/ordering.htm 


\section{Executive Summary}

This report documents the structural and modal properties of the blade and the tower of a three-bladed $750 \mathrm{~kW}$ upwind turbine, which has been selected for the Gearbox Reliability Collaborative (GRC) currently in progress. The collaborative needs these properties to be entered into the FAST computer program [1] to develop an aeroelastic model of the GRC turbine. Loads obtained from this model are intended to numerically analyze the GRC drivetrain and to guide the dynamometer testing. However, the distributed structural properties and modes, for either the blade or the tower, were not available from the turbine manufacturer.

NREL test engineers performed quick tests on the GRC turbine and collected limited experimental data. Using this data, we used the technique of finite-element updating to estimate the properties of the blade and the tower. BModes [2], a finite-element code developed for modal analysis of rotor blades and towers, was used to aid model updating and to compute the complete set of mode shapes and structural properties required by FAST.

For the GRC blade, though no measured distributed properties or drawings were available, we acquired some experimental data: the blade total mass, center-of-mass location, the chord and twist geometry, and the first three modal frequencies. To ensure that the estimated properties of the GRC blade were as realistic as possible, we first sought a blade that best resembled the GRC blade (in terms of length, total mass, and power rating) and for which properties were available. The WindPACT blade, investigated under the WindPact studies [3], met these criteria. Using distributed properties of the WindPACT blade, we first built its finite element model and computed its frequencies and mode shapes using BModes.

Next, using an iterative model updating scheme, we incrementally modified the model until its computed modal frequencies, total mass, and center of mass location matched the corresponding measured quantities for the GRC blade. We made no attempt to match the mode shapes because of the lack of corresponding measured data. From the final updated finite-element model, we determined the GRC blade modes shapes and also extracted the distributed structural properties, i.e. the span-varying inertias and stiffness, using a least-square approach.

For the GRC tower, we determined the tower distributed properties using the available drawings. The computation of tower modes, however, required knowledge of the tower-head mass and inertia, which we estimated from the Weights, Dimensions \& Transport Guidelines document available for the GRC turbine. While we could accord a high level of confidence to the distributed properties of the tower because of its simple geometry and available drawings, we could not do the same to its head inertia or its foundation flexibility. We again used BModes for tower model updating. Owing to the simplicity of the tower geometry, however, the updating of the tower model was straightforward. As with the blade model, we used the final tuned model to compute tower modes and properties required for FAST modeling. For both the blade and the tower, we also show comparison of the distributed properties and mode shapes of the original and the updated models. 


\section{Contents}

Page

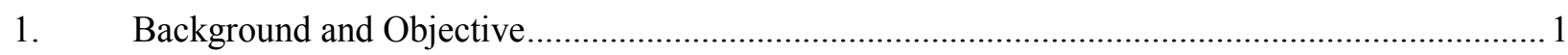

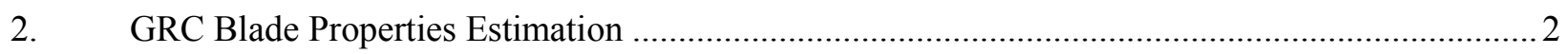

2.1. Baseline Blade Structural Properties and Modes...................................................................... 2

2.2. Experimental Data for the GRC Turbine Blade ................................................................... 5

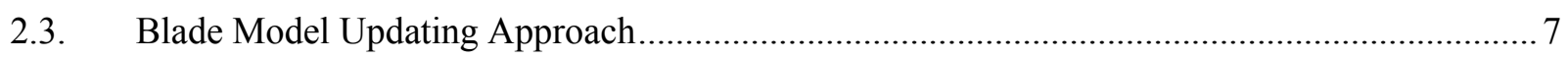

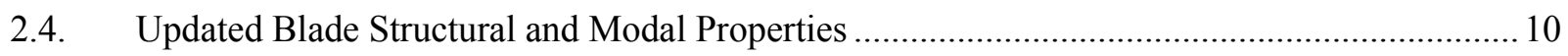

2.5. Comparison of Baseline and Updated Blade Models ............................................................ 12

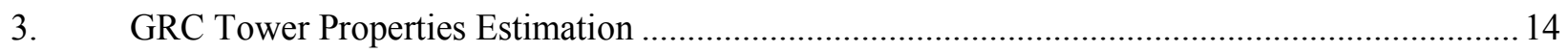

3.1. Baseline Tower Structural Properties and Modes ............................................................. 14

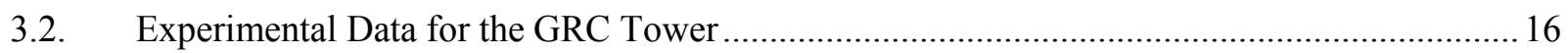

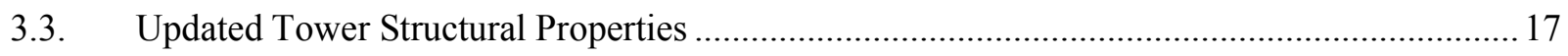

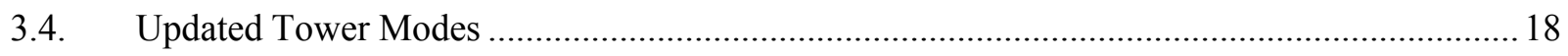

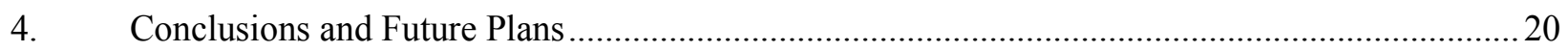

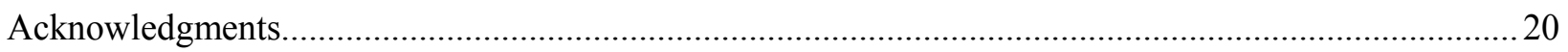

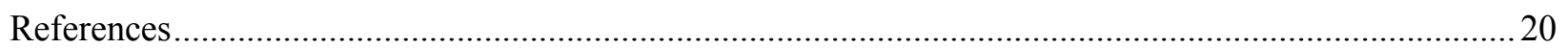




\section{List of Figures}

Figure 1: Baseline (WindPact) blade $1^{\text {st }}$ flap mode ......................................................................... 4

Figure 2: Baseline (WindPact) blade $2^{\text {nd }}$ flap mode........................................................................ 4

Figure 3: Baseline (WindPact) blade $1^{\text {st }}$ edge mode ............................................................................ 5

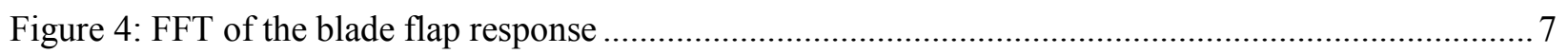

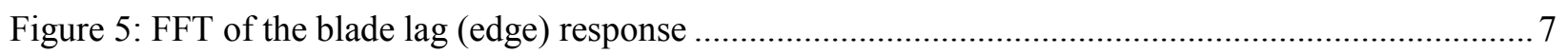

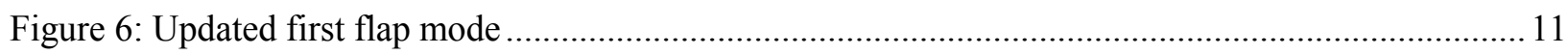

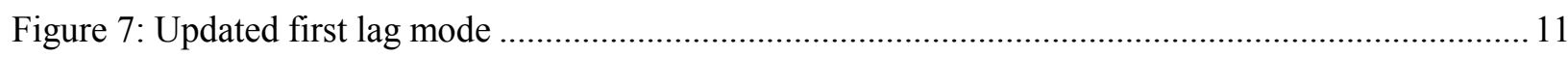

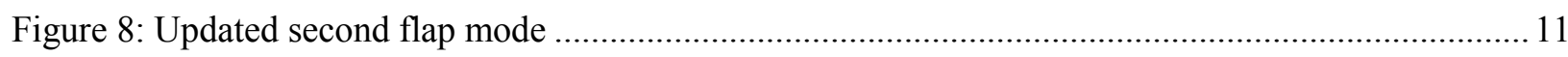

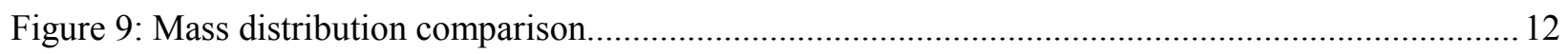

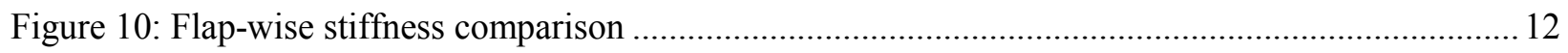

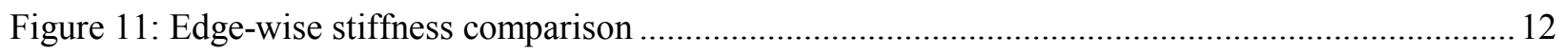

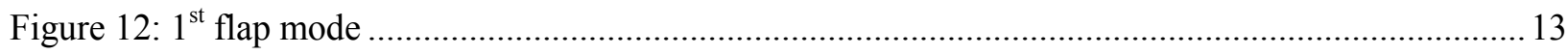

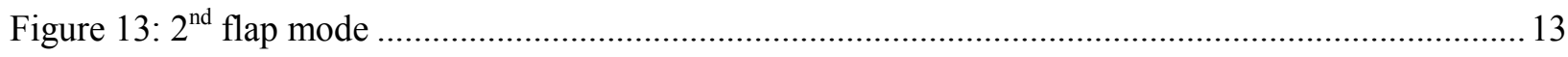

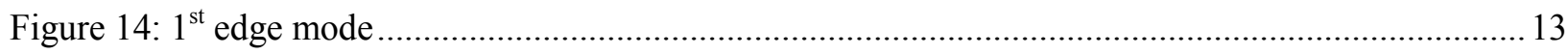

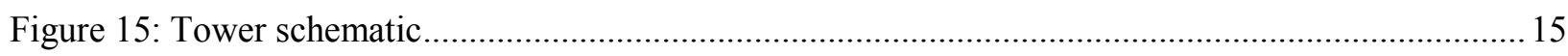

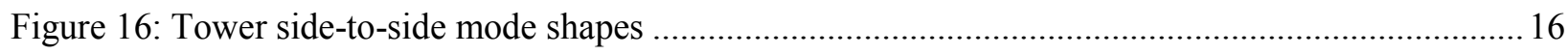

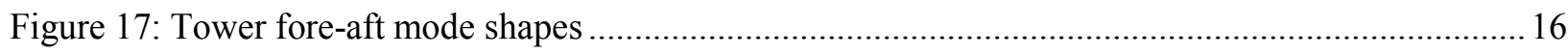

Figure 18: Experimentally determined tower side-to-side sway frequency response .............................. 17

Figure 19: Tower flexural stiffness variation along its length ............................................................ 18

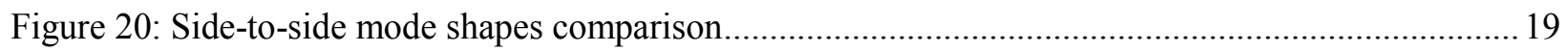

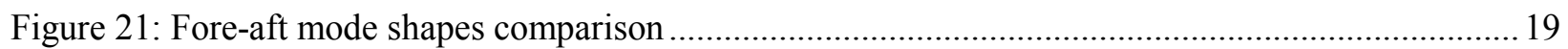




\section{List of Tables}

Table 1: Baseline Blade Structural Properties 3

Table 2: Experimentally determined data for the GRC blade 5

Table 3: Twist and chord distribution for the GRC blade $\quad 6$

Table 4: Comparison of GRC-blade experimental data with similar baseline-blade data 7

Table 5: Updated blade structural parameters $\quad 10$

Table 6: Polynomial approximations of the mode shapes 11

Table 7: Comparison of updated-blade and experimentally determined GRC-blade frequencies 14

Table 8: GRC tower dimensions 14

Table 9: Baseline tower structural properties 15

Table 10: Tower-head properties 15

Table 11: Tower head mass properties $\quad 18$

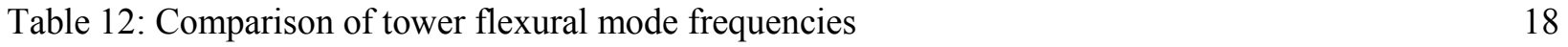

Table 13: Polynomial expressions of the tower modes 20 


\section{Background and Objective}

One of the requirements of the Gearbox Reliability Collaborative (GRC), currently in progress, is to create a model of the GRC turbine using the Fatigue, Aerodynamics, Structures, and Turbulence (FAST) [1] computer program. The GRC turbine is a three-bladed 750-kW upwind turbine selected for the collaborative effort. FAST requires these properties to develop an aeroelastic model of the turbine. Loads predicted by this model will be used to guide the dynamometer testing and for numerical analysis of the GRC drivetrain using SimPack [4]. However, to build the aeroelastic model, FAST needs structural properties and modal characteristics of the GRC turbine blade and tower. This report documents these properties and briefly describes how they are obtained. For both the blade and the tower, only limited experimental modal data are available and, therefore, the technique of finite-element updating has been used to estimate their structural properties. The finite-element code BModes was used to aid finite-element updating and also to compute the complete set of mode shapes and structural properties required by FAST.

For the GRC blade, no measured distributed properties or drawings were available. We had, however, access to the blade total mass, center-of-mass location, the chord and twist geometry, and the first few modal frequencies, which were measured by NREL test engineers. To ensure that the estimated properties of the GRC blade are as realistic as possible, we first sought a blade that best resembled the GRC blade (in terms of length, total mass, and power rating) and for which properties were available. The WindPACT blade, investigated under the WindPact studies [3], met these criteria. Using distributed properties of the WindPACT blade, we first built its finite element model and computed its frequencies and mode shapes using BModes. Next, using an iterative model updating scheme, we incrementally modified the model until its computed modal frequencies, total mass, and center of mass location matched the corresponding measured quantities for the GRC blade. We made no attempt to match the mode shapes because of the lack of corresponding measured data. From the final updated finite-element model, we determined the GRC blade modes shapes and also extracted the distributed structural properties, i.e., the span-varying inertias and stiffness, using a least-square approach.

For the GRC tower, we determined the tower distributed properties using the available drawings. The computation of tower modes, however, required knowledge of the tower-head mass and inertia, which we estimated from the Weights, Dimensions \& Transport Guidelines document available for the GRC turbine. While we could accord a high level of confidence to the distributed properties of the tower because of its simple geometry and available drawings, we could not do the same to its head inertia or its foundation flexibility. We again used BModes for tower model updating. Owing to the simplicity of the tower geometry, however, the updating of the tower model was relatively straightforward. As with the blade model, we used the final updated model to compute tower modes and properties required for FAST modeling. For both the blade and the tower, we also show comparison of the distributed properties and mode shapes of the original and the updated models

Note that we had only limited experimental data available to match. For example, no measured mode shapes were available to be matched by the updated models. Therefore, the model updating scheme we used was less complex than what would have been required otherwise. The downside is that mode shapes predicted by our updated models may not exactly match those for the actual blade or the tower. The updated models can be only as good as the available data. We match all available data. To enforce certain physical constraints and to meet time deadlines, however, we had to combine the formal updating scheme with a few trial-and-error steps. 
Realizing frequent need by the industry to estimate distributed structural properties of actual blades and towers, for which reliable distributed data are rarely available and difficult and expensive to measure, we plan to extend the system identification (updating) technique in the future for broader applications and for a broader range of test data availability. The emphasis in this report is on documentation of the GRC blade and the tower properties; the updating process is only briefly mentioned. We will publish the complete updating procedure after we refine and extend the system identification technique for broader applications.

Organization of this report is as follows. Section 2 focuses on the GRC blade and shows how its properties (structural and modal) are estimated. We begin with a baseline blade (WindPACT blade) that is close to the GRC blade in terms of length and power rating. We list its properties and also show its modes obtained using BModes. Then, we briefly describe the updating scheme that results in an updated model whose frequencies and other characteristics match the GRCblade characteristics obtained experimentally. We present structural and modal properties of the updated blade and compare these with those of the baseline blade. Section 3 focuses on the tower and is similarly organized. Section 4 summarizes conclusions and future plans.

\section{GRC Blade Properties Estimation}

To estimate the GRC blade properties, we select the WindPACT blade as our baseline blade; its properties are likely closest to that of the GRC blade. This is because its length $(23.3 \mathrm{~m})$ is close to the GRC-blade length $(23.5 \mathrm{~m})$ and the WindPACT turbine power rating equals the GRC turbine rating $(750 \mathrm{~kW})$. Section 2.1 presents the baseline blade distributed properties and its modes. Section 2.2 describes the GRC blade experimental test data. Section 2.3 outlines how we incrementally update the baseline model until its characteristics match the experimental data for the GRC blade. Section 2.4 presents structural and modal properties of the updated blade and Section 2.5 compares these with those of the baseline blade.

\subsection{Baseline Blade Structural Properties and Modes}

The baseline blade distributed structural properties are shown in Table 1; these are acquired from the WindPACT studies [3]. The properties are tabulated at 21 stations; the second column of the Table lists each station distance from the blade root normalized with respect to the blade length $(23.3 \mathrm{~m})$. The other columns show the distributed properties (columns 3-5: inertia properties, column 6: section center of-mass location with respect to the blade pitch axis, columns 7: section shear-center location with respect to the blade pitch axis). Table 1(continued) provides the other distributed properties (column 2: twist distribution, columns 3-6: stiffness properties, columns 78: aerodynamic properties). We used trapezoidal integration to obtain the blade mass $(1562.3 \mathrm{~kg})$ and the blade center-of-mass location with respect to the blade root $(7.029 \mathrm{~m})$.

We input these properties to BModes, which yielded the modal frequencies and corresponding modes. The BModes-based finite element model required 13 elements to obtain convergence of the first four frequencies within $1 \%$. BModes yielded many frequencies, $9 * N_{e}-6$ to be exact, where $N_{e}$ is the number of elements selected to discretize the blade. Also, it yielded coupled modes (a particular mode shows coupling between some or all of the following blade displacements: flap, lag, twist, and axial extension). However, FAST, which we plan to use for GRC turbine modeling, accepts only three uncoupled modes: the first two flap modes and the first lag mode. 
Table 1: Baseline Blade Structural Properties

\begin{tabular}{|c|c|c|c|c|c|c|}
\hline Number & $\begin{array}{c}\text { Fraction of } \\
\text { Blade Length } \\
\mathrm{X} / \mathrm{L}^{*}\end{array}$ & $\begin{array}{l}\text { Mass/Length } \\
(\mathrm{kg} / \mathrm{m})\end{array}$ & $\begin{array}{c}\text { Flap } \\
\text { Inertia, ly } \\
\left(\mathrm{kg}-\mathrm{m}^{\wedge} 2\right)\end{array}$ & $\begin{array}{c}\text { Lag Inertia } \\
\text { ly } \\
\left(\mathrm{kg}-\mathrm{m}^{\wedge} 2\right)\end{array}$ & $\underset{(\mathrm{m})}{\mathrm{y} \text { cg_offset }}$ & $\begin{array}{c}\text { y_ea_offset } \\
(\mathrm{m})\end{array}$ \\
\hline 1 & $0.000 \mathrm{E}+00$ & $7.134 \mathrm{E}+02$ & $2.256 \mathrm{E}+02$ & $5.640 \mathrm{E}+01$ & 0.000 & 0.000 \\
\hline 2 & $2.105 \mathrm{E}-02$ & $9.981 \mathrm{E}+01$ & $3.157 \mathrm{E}+01$ & $7.891 \mathrm{E}+00$ & 0.000 & 0.000 \\
\hline 3 & 5.263E-02 & $1.013 \mathrm{E}+02$ & $2.962 \mathrm{E}+01$ & $7.406 \mathrm{E}+00$ & 0.018 & -0.005 \\
\hline 4 & 1.053E-01 & $1.037 \mathrm{E}+02$ & $2.639 \mathrm{E}+01$ & $6.597 \mathrm{E}+00$ & 0.049 & -0.013 \\
\hline 5 & 1.579E-01 & $1.061 \mathrm{E}+02$ & $2.315 \mathrm{E}+01$ & $5.788 \mathrm{E}+00$ & 0.079 & -0.022 \\
\hline 6 & $2.105 \mathrm{E}-01$ & $1.085 \mathrm{E}+02$ & $1.991 \mathrm{E}+01$ & $4.978 \mathrm{E}+00$ & 0.110 & -0.030 \\
\hline 7 & 2.632E-01 & $9.975 \mathrm{E}+01$ & $1.721 \mathrm{E}+01$ & $4.303 E+00$ & 0.113 & -0.020 \\
\hline 8 & 3.158E-01 & $9.095 \mathrm{E}+01$ & $1.451 \mathrm{E}+01$ & $3.628 \mathrm{E}+00$ & 0.115 & -0.009 \\
\hline 9 & 3.684E-01 & $8.216 \mathrm{E}+01$ & $1.181 \mathrm{E}+01$ & $2.953 \mathrm{E}+00$ & 0.118 & 0.002 \\
\hline 10 & $4.211 \mathrm{E}-01$ & $7.337 \mathrm{E}+01$ & $9.111 \mathrm{E}+00$ & $2.278 \mathrm{E}+00$ & 0.120 & 0.013 \\
\hline 11 & 4.737E-01 & $6.458 \mathrm{E}+01$ & $6.410 \mathrm{E}+00$ & $1.603 \mathrm{E}+00$ & 0.123 & 0.024 \\
\hline 12 & $5.263 \mathrm{E}-01$ & $5.682 \mathrm{E}+01$ & $5.377 \mathrm{E}+00$ & $1.344 \mathrm{E}+00$ & 0.124 & 0.029 \\
\hline 13 & 5.789E-01 & $4.907 \mathrm{E}+01$ & $4.344 \mathrm{E}+00$ & $1.086 \mathrm{E}+00$ & 0.125 & 0.034 \\
\hline 14 & 6.316E-01 & $4.131 \mathrm{E}+01$ & $3.311 \mathrm{E}+00$ & $8.278 \mathrm{E}-01$ & 0.126 & 0.039 \\
\hline 15 & $6.842 \mathrm{E}-01$ & $3.356 \mathrm{E}+01$ & $2.278 \mathrm{E}+00$ & $5.695 \mathrm{E}-01$ & 0.127 & 0.044 \\
\hline 16 & 7.368E-01 & $2.581 \mathrm{E}+01$ & $1.245 \mathrm{E}+00$ & 3.112E-01 & 0.128 & 0.049 \\
\hline 17 & 7.895E-01 & $2.169 \mathrm{E}+01$ & $1.013 \mathrm{E}+00$ & 2.533E-01 & 0.127 & 0.050 \\
\hline 18 & 8.421E-01 & $1.757 \mathrm{E}+01$ & $7.815 \mathrm{E}-01$ & 1.954E-01 & 0.125 & 0.051 \\
\hline 19 & 8.947E-01 & $1.345 \mathrm{E}+01$ & $5.498 \mathrm{E}-01$ & 1.375E-01 & 0.124 & 0.052 \\
\hline 20 & 9.474E-01 & $9.326 \mathrm{E}+00$ & 3.182E-01 & 7.954E-02 & 0.122 & 0.053 \\
\hline 21 & $1.000 \mathrm{E}+00$ & $5.206 \mathrm{E}+00$ & 8.649E-02 & $2.162 \mathrm{E}-02$ & 0.121 & 0.054 \\
\hline
\end{tabular}

Table 1 (continued): Baseline Blade Structural Properties

\begin{tabular}{|c|c|c|c|c|c|c|c|}
\hline Number & $\begin{array}{l}\text { Twist } \\
\text { (deg) }\end{array}$ & $\begin{array}{l}\text { GJ (N- } \\
\left.\mathrm{m}^{\wedge} 2\right)\end{array}$ & $E A(N)$ & $\begin{array}{c}\text { Edge, Elz } \\
\left(\mathrm{N}-\mathrm{m}^{\wedge} 2\right)\end{array}$ & $\begin{array}{l}\text { Flap, Eiy } \\
\left(\mathrm{N}-\mathrm{m}^{\wedge} 2\right)\end{array}$ & $\begin{array}{l}\text { Chord } \\
(\mathrm{m})\end{array}$ & $\underset{(\mathrm{m})}{\text { y_ac_offset }}$ \\
\hline 1 & 11.1 & $6.6 \mathrm{E}+08$ & $9.621 \mathrm{E}+09$ & $1.912 \mathrm{E}+09$ & $1.912 \mathrm{E}+09$ & 1.257 & 0.000 \\
\hline 2 & 11.1 & $1.09 \mathrm{E}+08$ & $1.595 \mathrm{E}+09$ & $3.129 \mathrm{E}+08$ & $3.129 \mathrm{E}+08$ & 1.257 & 0.000 \\
\hline 3 & 11.1 & 93127094 & $1.585 \mathrm{E}+09$ & $2.977 \mathrm{E}+08$ & $2.739 \mathrm{E}+08$ & 1.397 & -0.031 \\
\hline 4 & 11.1 & 66122588 & $1.569 E+09$ & $2.725 \mathrm{E}+08$ & $2.091 \mathrm{E}+08$ & 1.631 & -0.084 \\
\hline 5 & 11.1 & 39118082 & $1.553 \mathrm{E}+09$ & $2.472 \mathrm{E}+08$ & $1.442 \mathrm{E}+08$ & 1.864 & -0.136 \\
\hline 6 & 11.1 & 12113576 & $1.537 \mathrm{E}+09$ & $2.220 \mathrm{E}+08$ & $7.928 \mathrm{E}+07$ & 2.097 & -0.189 \\
\hline 7 & 9.5 & 10741288 & $1.420 \mathrm{E}+09$ & $1.928 \mathrm{E}+08$ & $6.726 \mathrm{E}+07$ & 1.987 & -0.170 \\
\hline 8 & 7.9 & 9369000 & $1.302 \mathrm{E}+09$ & $1.635 \mathrm{E}+08$ & $5.525 \mathrm{E}+07$ & 1.876 & -0.150 \\
\hline 9 & 6.3 & 7996713 & $1.185 \mathrm{E}+09$ & $1.343 \mathrm{E}+08$ & $4.323 \mathrm{E}+07$ & 1.766 & -0.131 \\
\hline 10 & 4.7 & 6624425 & $1.067 \mathrm{E}+09$ & $1.051 \mathrm{E}+08$ & $3.121 \mathrm{E}+07$ & 1.656 & -0.112 \\
\hline 11 & 3.1 & 5252137 & $9.497 \mathrm{E}+08$ & $7.590 \mathrm{E}+07$ & $1.919 \mathrm{E}+07$ & 1.546 & -0.093 \\
\hline 12 & 2.6 & 4300745 & $8.316 \mathrm{E}+08$ & $6.380 \mathrm{E}+07$ & $1.578 \mathrm{E}+07$ & 1.435 & -0.080 \\
\hline 13 & 2.1 & 3349352 & $7.134 \mathrm{E}+08$ & $5.170 \mathrm{E}+07$ & $1.237 \mathrm{E}+07$ & 1.325 & -0.068 \\
\hline 14 & 1.6 & 2397959 & $5.953 \mathrm{E}+08$ & $3.960 \mathrm{E}+07$ & $8.963 \mathrm{E}+06$ & 1.215 & -0.055 \\
\hline 15 & 1.1 & 1446566 & $4.772 \mathrm{E}+08$ & $2.750 \mathrm{E}+07$ & $5.554 \mathrm{E}+06$ & 1.105 & -0.042 \\
\hline 16 & 0.6 & 495173.7 & $3.590 \mathrm{E}+08$ & $1.540 \mathrm{E}+07$ & $2.144 \mathrm{E}+06$ & 0.994 & -0.030 \\
\hline 17 & 0.48 & 396604.6 & $2.917 \mathrm{E}+08$ & $1.255 \mathrm{E}+07$ & $1.722 \mathrm{E}+06$ & 0.895 & -0.024 \\
\hline 18 & 0.36 & 298035.6 & $2.244 \mathrm{E}+08$ & $9.709 \mathrm{E}+06$ & $1.300 \mathrm{E}+06$ & 0.796 & -0.018 \\
\hline 19 & 0.24 & 199466.6 & $1.570 \mathrm{E}+08$ & $6.865 \mathrm{E}+06$ & $8.786 \mathrm{E}+05$ & 0.697 & -0.012 \\
\hline 20 & 0.12 & 100897.5 & $8.969 \mathrm{E}+07$ & $4.021 \mathrm{E}+06$ & $4.567 \mathrm{E}+05$ & 0.598 & -0.006 \\
\hline 21 & 0 & 2328.49 & $2.235 \mathrm{E}+07$ & $1.177 \mathrm{E}+06$ & $3.492 \mathrm{E}+04$ & 0.498 & 0.000 \\
\hline
\end{tabular}

Uncoupled modes from BModes can be obtained in two ways. We can either set all section centers-of-mass and shear-center offsets to zero in the data that are input to BModes, or we can 
ignore secondary-motion participations in a particular mode (e.g., if the mode is flap-lag coupled with a dominant flap motion, we can ignore the lag motion contribution to obtain the uncoupled flap mode). We chose the second way for two reasons. First, for a better model updating, we did need the original uncoupled modes. Second, a modeling approximation is achieved if we use uncoupled modes, obtained the second way, in a modal-based code such as FAST.

Figures 1and 2 show the $1^{\text {st }}$ and $2^{\text {nd }}$ flap modes and Figure 3 shows the $1^{\text {st }}$ lag mode for the baseline blade. The corresponding frequencies are $1.92 \mathrm{~Hz}, 3.06 \mathrm{~Hz}$, and $5.14 \mathrm{~Hz}$. The dominant displacement in each coupled mode, which designates the mode, is shown as a bold line, whereas the secondary displacement is shown as a dotted line. Note that there are no unity tip displacements because BModes generates mass-normalized mode shapes.

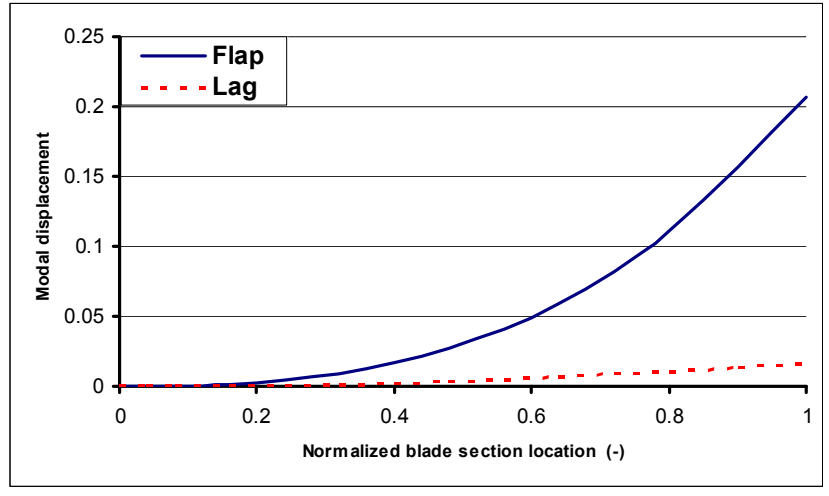

Figure 1: Baseline (WindPact) blade $1^{\text {st }}$ flap mode

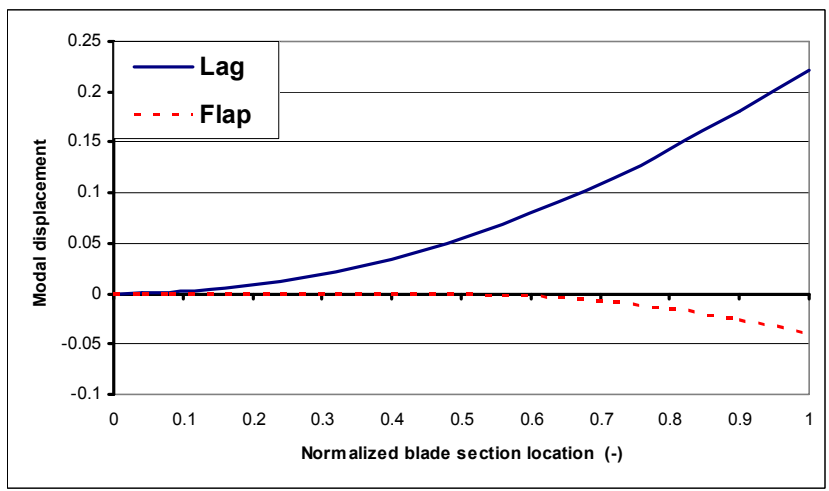

Figure 2: Baseline (WindPact) blade $2^{\text {nd }}$ flap mode 


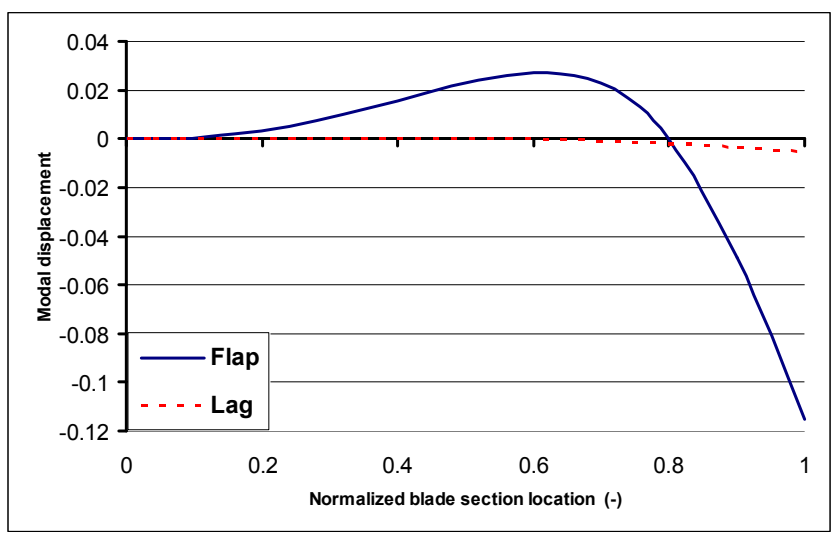

Figure 3: Baseline (WindPact) blade $1^{\text {st }}$ edge mode

\subsection{Experimental Data for the GRC Turbine Blade}

Distributed properties for the GRC blade, with the exception of twist, chord, and a few modal frequencies, were not available and we needed these properties to build the GRC turbine model. Direct measurement of these properties is difficult, time-intensive, and may require destructive testing. To infer these properties, therefore, we must have other information about the blade, which is most reliably obtained experimentally. Examples of such blade information are its total mass, its center-of-mass location, and its mode shapes. NREL test engineers obtained the first two modal frequencies. The blade total mass and the center-of-mass location were determined from the general blade properties available from the Weights, Dimensions \& Transport Guidelines document for the GRC turbine. Table 2 shows the measured blade frequencies, the total blade mass, blade length, and the blade center-of-mass location. Twist and chord distribution along the blade are provided in Table 3.

Mode shapes were not obtained experimentally because of the time and data-acquisition constraints and the requirement of elaborate instrumentation. Modal frequencies are inferred from Fast Fourier Transforms (FFTs) of the blade free-response data obtained experimentally. These FFTs are shown in Figures 4 and 5. Only two modal frequencies can be inferred reliably from this data; other modes probably were not sufficiently excited to show up in the FFTs. These frequencies are presented in Table 2 and also identified in Figures 4 and 5.

Table 2: Experimentally determined data for the GRC blade

\begin{tabular}{|c|c|}
\hline \multicolumn{2}{|c|}{ Blade Characteristics } \\
\hline \multicolumn{2}{|c|}{ Frequency Hz } \\
\hline 1.72 & $1^{\text {st }}$ Flap \\
\hline 2.41 & $1^{\text {st }}$ Edge \\
\hline 4.84 & $2^{\text {nd }}$ Flap \\
\hline \multicolumn{2}{|c|}{ Mass } \\
\hline 3400 & Length \\
\hline \multicolumn{2}{|c|}{ (m) } \\
\hline 23.5 & (m) \\
\hline \multicolumn{2}{|c|}{ Blade center-of-mass } \\
location from the blade root
\end{tabular}


Table 3: Twist and chord distribution for the GRC blade

\begin{tabular}{|c|c|c|c|}
\hline Station & $\begin{array}{c}\text { Twist } \\
\text { wrt Hub }\end{array}$ & $\begin{array}{l}\text { Chord } \\
\text { length }\end{array}$ & Comments \\
\hline [m] & [deg] & {$[\mathrm{mm}]$} & \\
\hline 0.00 & & 1330.00 & \multirow{7}{*}{$\begin{array}{l}\text { Large } \\
\text { Calipers }\end{array}$} \\
\hline 3.66 & 16.00 & 1845.00 & \\
\hline 4.88 & 18.10 & 2155.00 & \\
\hline 6.10 & 17.20 & 2265.00 & \\
\hline 7.01 & 14.70 & 2205.00 & \\
\hline 8.23 & 12.30 & 2135.00 & \\
\hline 10.06 & 10.50 & 2075.00 & \\
\hline 10.06 & 9.00 & 1984.00 & \multirow{14}{*}{$\begin{array}{l}\text { Medium } \\
\text { Calipers }\end{array}$} \\
\hline 10.97 & 7.80 & 1909.00 & \\
\hline 11.89 & 7.10 & 1824.00 & \\
\hline 12.80 & 6.10 & 1747.00 & \\
\hline 13.72 & 5.20 & 1667.00 & \\
\hline 14.63 & 4.50 & 1575.00 & \\
\hline 15.54 & 3.80 & 1493.00 & \\
\hline 16.46 & 2.90 & 1389.00 & \\
\hline 17.37 & 2.40 & 1286.00 & \\
\hline 18.29 & 2.00 & 1187.50 & \\
\hline 19.20 & 1.30 & 1156.00 & \\
\hline 20.07 & 1.10 & 989.00 & \\
\hline 20.07 & 1.10 & 916.00 & \\
\hline 20.80 & 0.60 & 834.00 & \\
\hline 20.80 & 0.80 & 873.00 & \multirow{3}{*}{$\begin{array}{l}\text { Small } \\
\text { Calipers }\end{array}$} \\
\hline 21.72 & 0.30 & 752.00 & \\
\hline 22.63 & -0.70 & 640.00 & \\
\hline
\end{tabular}

To measure the blade frequencies, free-response data were collected from two uni-axial accelerometers placed at the point where the blade's aerodynamic brake starts, specifically at the 20.066-m location from the root. One accelerometer was oriented perpendicular to the local chord to capture the flap response, and the other parallel to it to capture the lag response. The blade was excited manually to obtain the desired blade response. Once the blade was excited it was allowed to oscillate freely until the excitation decayed. The blade pitch was set at 0.06 degree at its root during the experiment. We assume that the modal behavior was not influenced by such a small pitch inclination.

To ensure that the experimental data collected were accurate, the frequencies were compared with values provided by the manufacturer. The $1^{\text {st }}$ flap and the $1^{\text {st }}$ lag frequencies showed good concurrence. However, the FFT did not pick the $2^{\text {nd }}$ flap frequency, probably because it could not be sufficiently excited. Therefore, we selected the manufacturer-supplied value $(4.84 \mathrm{~Hz})$. 


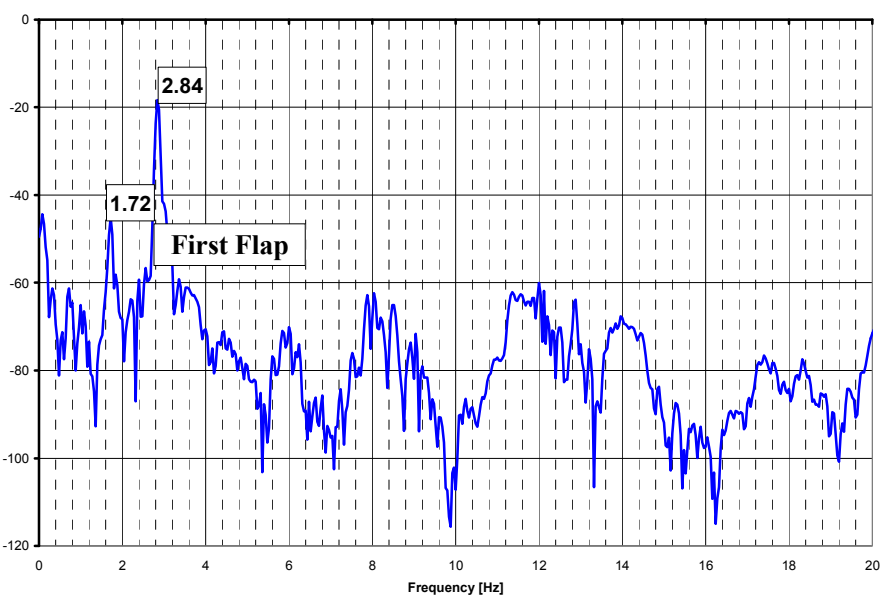

Figure 4: FFT of the blade flap response

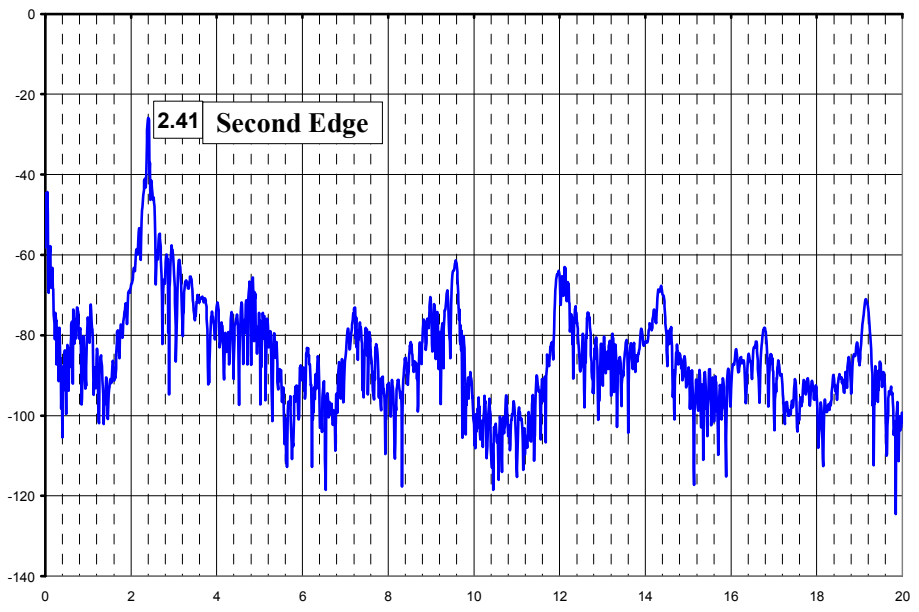

Figure 5: FFT of the blade lag (edge) response

\subsection{Blade Model Updating Approach}

The GRC blade experimental data differed from similar data for the baseline blade (see Table 4). We needed to update the baseline model to eliminate these discrepancies. Literature cites several updating schemes. References 5- 19 describe a few that are relevant to our problem. All these schemes attempt to update the finite element model so as to match the experimental frequencies and mode shapes.

Table 4: Comparison of GRC-blade experimental data with similar baseline-blade data

\begin{tabular}{|c|c|c|c|c|c|c|}
\hline & $\begin{array}{c}\text { Mass } \\
(\mathbf{K g})\end{array}$ & $\begin{array}{c}\text { Length } \\
(\mathbf{m})\end{array}$ & $\begin{array}{c}\text { C.G. } \\
\text { Location }(\mathbf{m})\end{array}$ & $\begin{array}{c}\mathbf{1}^{\text {st }} \text { Flap } \\
\text { Frequency } \\
(\mathbf{H z})\end{array}$ & $\begin{array}{c}\mathbf{1}^{\text {st }} \text { Lag } \\
\text { Frequency } \\
(\mathbf{H z})\end{array}$ & $\begin{array}{c}\text { 2nd Flap } \\
\text { Frequency } \\
(\mathbf{H z})\end{array}$ \\
\hline Baseline & 1562.3 & 23.3 & 7.029 & 1.92 & 3.06 & 5.14 \\
\hline GRC & 3400 & 23.5 & 7.417 & 1.72 & 2.41 & 4.84 \\
\hline
\end{tabular}

Matching the mode shapes in an update scheme can be particularly involved. However, we had to match only the frequencies (no mode shapes were available to match). This implied we could use 
a comparatively simple updating scheme. Note, though, that we needed to match the blade total mass and its center-of-mass location as well. Additionally, we needed to satisfy two constraints: a) the flap stiffness must equal the lag (edgewise) stiffness over the circular-section portion of the blade $(0-0.5 \mathrm{~m})$, and $\mathrm{b})$ the updated mass and stiffness values should be positive. This meant we required an updating technique akin to constrained optimization.

To minimize the number of iterations required in the model updating, we first increased the baseline blade length by a factor of 1.0084 and then scaled its mass distribution by a factor of 2.1763. This made the blade length equal to $23.5 \mathrm{~m}$ and its total mass equal to $3400 \mathrm{~kg}$, which exactly match the corresponding quantities for the GRC blade. Note, however, that center-ofmass location of this modified blade, which we call BL2, is $7.029 \mathrm{~m}$ and it does not yet match the target value of $7.417 \mathrm{~m}$.

Several updating schemes have been suggested in the literature. These may be classified into two categories: direct schemes [5-12] and implicit schemes [13-19]. The direct schemes directly use the modal data and lead to representational models, which may not be physically meaningful.

Consider the baseline blade model we are interested in updating. The finite element scheme in BModes models this blade in terms of a mass matrix $\left(M_{0}\right)$ and a stiffness matrix $\left(K_{0}\right)$. A direct updating scheme would use the experimental data and directly update the elements of these two matrices; it would not update the original blade properties. The updated mass and stiffness matrices, say $M$ and $K$, would be representational in the sense that they would yield modes that closely approximate the experimental modes. However, the updated $M$ and $K$ will not, in general, yield physically realizable blade properties. Note that the original mass and stiffness matrices, $M_{0}$ and $K_{0}$, are formulated using specified (physically realizable properties) and finite-element mode shapes. These matrices also satisfy certain displacement compatibility conditions.

The direct updating scheme disregards the element shape functions and has no mechanism to ensure compatibility either; it directly operates only on the elements of the mass and stiffness matrices. Consequently, a solution of the inverse problem, i.e., extracting blade properties from $M$ and $K$, may not yield meaningful results. Direct-scheme researchers have suggested ways to correct the finite element models to ensure that the updated $\mathrm{M}$ and $\mathrm{K}$ are at least analytically viable, i.e., they are positive definiteness and satisfy orthogonality of the finite element-model modes with the measured modes. These corrections, however, do not ensure that those finiteelement-model-predicted modes, for which no matching experimental data are available, would be representative of the actual system.

In an implicit scheme, blade properties are updated iteratively until the finite-element-generated $M$ and $K$ yield modes that closely match the experimental data. This scheme relies on sensitivity derivatives, which implicitly ensure compatibility of the experimental modes with the blade properties. For the implicit approach, we may use either the minimum variance method or the penalty function method. The minimum variance methods [17-19], which have their roots in the Bayesian estimation, assume that both the measurements and the initial estimate of the system parameters have errors, which may be expressed as variance matrices. Parameters are then updated to minimize variance. This method can suffer from convergence problems and is useful if the amount of measured data is large and has statistical errors. The other method, the penalty function method, is relatively straightforward and relies on minimizing some penalty function to update the system parameters. This is the method we used.

Let $\mathbf{m}$ be the vector of measured modal data, which, in our case, contain the three measured frequencies $\left(f_{m 1}, f_{m 2}, f_{m 3}\right)$, the total blade mass $\left(M_{m}\right)$, and the blade center-of-mass location $\left(X_{G m}\right)$.

$$
\mathbf{m}=\left[f_{m 1}, f_{m 2}, f_{m 3}, M_{m}, X_{G m}\right]^{T}
$$


Let $\mathbf{a}$ be the vector of corresponding analytical data:

$$
\mathbf{a}=\left[f_{1}, f_{2}, f_{3}, M, X_{G}\right]^{T}
$$

We use BModes to build the analytical finite element model and to compute the three frequencies $\left(f_{1}, f_{2}, f_{3}\right)$. Note that the finite-element model predicts a large number of frequencies, but we select only those that correspond to the measured modes. The total blade mass $(M)$ and the blade centerof-mass location $\left(X_{G}\right)$ are given by the integrals:

$$
\begin{aligned}
& M=\int_{0}^{L} m(x) d x \\
& X_{G}=\frac{1}{M} \int_{0}^{L} m(x) x d x
\end{aligned}
$$

where $m(x)$ is the mass per unit length of the blade at span location $x$. We use Gauss quadrature to compute the two integrals. Let

$$
\begin{aligned}
& \delta \mathbf{y}=\mathbf{m}-\mathbf{a}_{j}=\text { difference between measured and analytical output } \\
& \delta \mathbf{p}=\mathbf{p}_{j+1}-\mathbf{p}_{j}=\text { perturbation in the model parameters } \\
& \mathbf{S}_{j}=\text { the sensitivity matrix }
\end{aligned}
$$

Then, as a first approximation,

$$
\delta \mathbf{y}=\mathbf{S}_{j} \delta \mathbf{p}
$$

where the subscript $j$ refers to the $j^{\text {th }}$ iteration. The vector $\mathbf{p}$ of model parameters comprises the blade mass, flap stiffness, and lag stiffness distributed along the blade.

If the number of measurements exceeds the number of parameters, then the set of equations (6) is over-determined and we can use the least squares approach to update p. However, we are using a finite-element model. Therefore, the number of parameters far exceeds the number of measurements implying that equations (6) are under-determined. This means there are an infinite set of parameter differences that will satisfy equations (6). For the best choice of parameters we can either use the singular value decomposition (SVD) or the Moore-Penrose generalized inverse for under-determined equations. The problem may be posed as a constrained optimization problem:

$$
\begin{gathered}
\text { Minimize } \delta \mathbf{p}^{T} \mathbf{W}_{p} \delta \mathbf{p} \\
\text { subject to the constraints } \delta \mathbf{y}=\mathbf{S}_{j} \delta \mathbf{p}
\end{gathered}
$$

where $\mathbf{W}_{\mathrm{p}}$ is the weighting matrix, which must be positive definite. Using Lagrange multipliers, the solution to the constrained optimization problem is obtained as

$$
\mathbf{p}_{j+1}=\mathbf{p}_{j}+\mathbf{W}_{p}^{-1} \mathbf{S}_{j}^{T}\left[\mathbf{S}_{j} \mathbf{W}_{p}^{-1} \mathbf{S}_{j}^{T}\right]^{-1}\left(\mathbf{m}-\mathbf{a}_{j}\right)
$$

We used BModes in conjunction with a finite-difference scheme to obtain the sensitivity matrix, $\mathbf{S}_{\mathrm{j}}$, at each iteration step; this was the most computationally intensive task in the whole updating process. As for the selection of the weighting matrix, $\mathbf{W}_{\mathrm{p}}$, at each iteration step; we used engineering judgment; the goal was to enforce rapid convergence and to ensure smooth variation of parameters along the blade. Without a judicious selection of $\mathbf{W}_{\mathrm{p}}$ at an iteration step, the 
variation of final properties along the blade may show jumps, or even negative values, which are not present in a real blade.

\subsection{Updated Blade Structural and Modal Properties}

Because the updated blade model matches the GRC blade experimental data, we assume that it closely models the GRC blade. The updated-blade-model distributed properties are listed in Table 5. The Table lists only the updated distributed properties of the GRC blade, together with its twist and chord variation. This is the data subset FAST requires to model the blade. Note that mass/unit length, flap stiffness, and lag stiffness are the only properties that we could possibly update from the available experimental data. The other properties in Table 1, which could not be updated, are fortunately ignored by FAST.

Table 5: Updated blade structural parameters

\begin{tabular}{|c|c|c|c|c|}
\hline $\begin{array}{l}\text { Section } \\
\text { Number }\end{array}$ & $\begin{array}{l}\text { Normalized } \\
\text { Section } \\
\text { Location }\end{array}$ & $\begin{array}{l}\text { Mass/Length } \\
(\mathrm{kg} / \mathrm{m})\end{array}$ & $\begin{array}{l}\text { Flap Stiffness } \\
\left(N-m^{\wedge} 2\right)\end{array}$ & $\begin{array}{c}\text { Lag } \\
\text { Stiffness } \\
\text { (N-m^2) }\end{array}$ \\
\hline 1 & 0.000 & 1427.29 & $3.74 \mathrm{E}+09$ & $3.74 \mathrm{E}+09$ \\
\hline 2 & 0.021 & 200.79 & $6.12 \mathrm{E}+08$ & $6.12 E+08$ \\
\hline 3 & 0.053 & 205.39 & $5.36 \mathrm{E}+08$ & $4.47 E+08$ \\
\hline 4 & 0.105 & 213.15 & $4.09 \mathrm{E}+08$ & $4.09 E+08$ \\
\hline 5 & 0.158 & 221.05 & $2.82 \mathrm{E}+08$ & $3.71 \mathrm{E}+08$ \\
\hline 6 & 0.211 & 229.08 & $1.55 \mathrm{E}+08$ & $3.33 E+08$ \\
\hline 7 & 0.263 & 213.27 & $1.32 \mathrm{E}+08$ & $2.89 E+08$ \\
\hline 8 & 0.316 & 196.96 & $1.08 \mathrm{E}+08$ & $2.45 E+08$ \\
\hline 9 & 0.368 & 180.18 & $8.45 \mathrm{E}+07$ & $2.02 \mathrm{E}+08$ \\
\hline 10 & 0.421 & 162.91 & $6.10 \mathrm{E}+07$ & $1.58 \mathrm{E}+08$ \\
\hline 11 & 0.474 & 145.16 & $3.77 \mathrm{E}+07$ & $1.14 \mathrm{E}+08$ \\
\hline 12 & 0.526 & 129.29 & $3.13 \mathrm{E}+07$ & $9.57 E+07$ \\
\hline 13 & 0.579 & 113.00 & $2.49 \mathrm{E}+07$ & $7.75 \mathrm{E}+07$ \\
\hline 14 & 0.632 & 96.28 & $1.84 \mathrm{E}+07$ & $5.94 \mathrm{E}+07$ \\
\hline 15 & 0.684 & 79.13 & $1.18 \mathrm{E}+07$ & $4.12 \mathrm{E}+07$ \\
\hline 16 & 0.737 & 61.56 & $5.18 \mathrm{E}+06$ & $2.31 \mathrm{E}+07$ \\
\hline 17 & 0.789 & 52.33 & $4.28 \mathrm{E}+06$ & $1.88 \mathrm{E}+07$ \\
\hline 18 & 0.842 & 42.87 & $3.31 \mathrm{E}+06$ & $1.46 \mathrm{E}+07$ \\
\hline 19 & 0.895 & 33.18 & $2.27 \mathrm{E}+06$ & $1.03 E+07$ \\
\hline 20 & 0.947 & 23.27 & $1.18 \mathrm{E}+06$ & $6.03 E+06$ \\
\hline 21 & 1.000 & 13.13 & $6.83 \mathrm{E}+04$ & $1.77 \mathrm{E}+06$ \\
\hline
\end{tabular}

As pointed out in Section 2.1, FAST also needs mode shapes to build the blade model. We input updated-blade properties to BModes, which yielded several coupled modes. From these, FAST required only the first two flap modes and the first lag mode; these are shown in Figures 6-8.

Frequencies of the $1^{\text {st }}$ flap, $2^{\text {nd }}$ flap, and $1^{\text {st }}$ lag modes are $1.72 \mathrm{~Hz}, 4.84 \mathrm{~Hz}$, and $2.41 \mathrm{~Hz}$ respectively.

The modes shown in the figures are mass-normalized. However, FAST requires that all modes be scaled for unity displacement at the blade tip; it also requires that each mode be approximated as a 6th-order polynomial. We used a least-square-fit approach to obtain such polynomial expressions for the three modes; Table 6 lists these expressions. Note that all polynomials satisfy the zero-displacement and zero-slope boundary conditions at the blade root and unit-displacement condition at the tip.

In summary, FAST uses the structural properties listed in Table 5 and the polynomial approximations of the mode shapes listed in Table 6 to build the GRC blade model. 


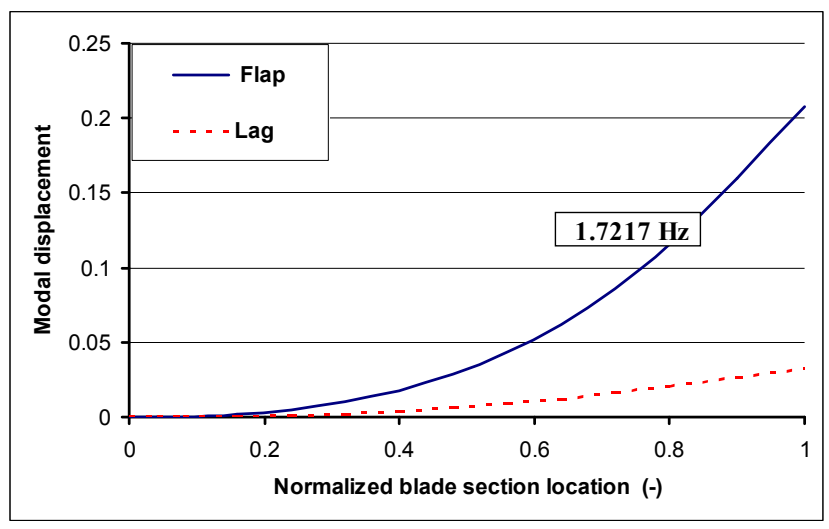

Figure 6: Updated first flap mode

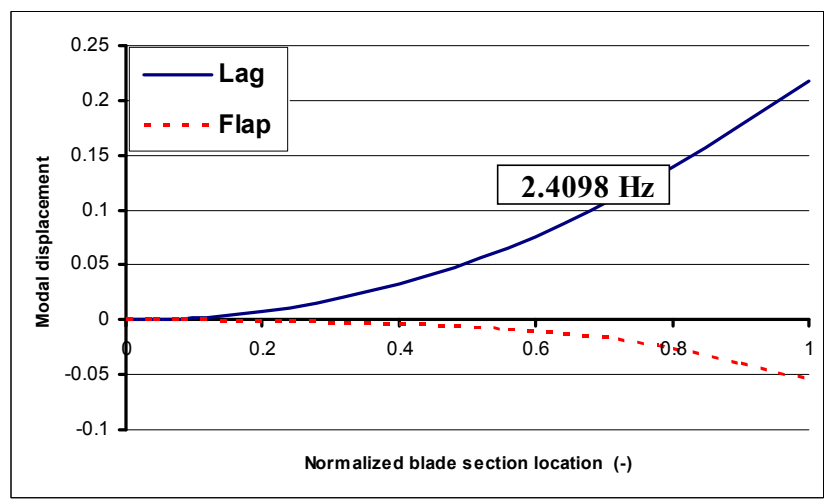

Figure 7: Updated first lag mode

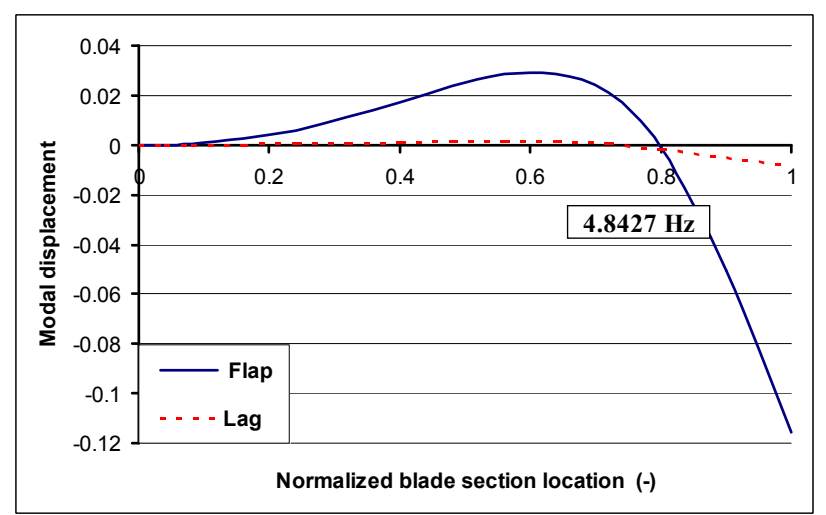

Figure 8: Updated second flap mode

Table 6: Polynomial approximations of the mode shapes

\begin{tabular}{|c|c|c|c|c|c|c|}
\hline \multirow{2}{*}{$\frac{\text { Mode }}{1 \text { st Flap }}$} & \multirow{2}{*}{$\begin{array}{c}\begin{array}{c}\text { Frequency } \\
(\mathrm{Hz})\end{array} \\
1.72170 \\
\end{array}$} & \multicolumn{5}{|c|}{$\begin{array}{l}\text { Polynomial Terms } \\
X^{3}+\end{array}$} \\
\hline & & 0.02395 & 2.2453 & -4.1649 & 5.1454 & -2.2498 \\
\hline 1st Lag & 2.40980 & 0.69226 & 1.2286 & -2.4026 & 2.5294 & -1.0477 \\
\hline 2nd Flap & 4.84270 & -1.92770 & 10.168 & -34.565 & 46.353 & -19.029 \\
\hline
\end{tabular}




\subsection{Comparison of Baseline and Updated Blade Models}

Figures 9-11 compare mass and stiffness properties of the baseline and updated blades, offering an insight into the modifications required in the baseline-blade properties so as to match the GRC blade experimental data.

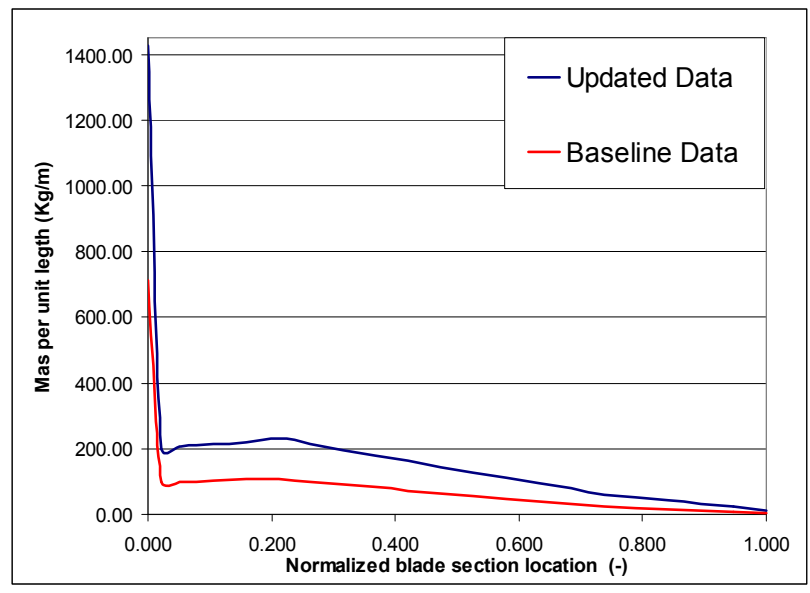

Figure 9: Mass distribution comparison

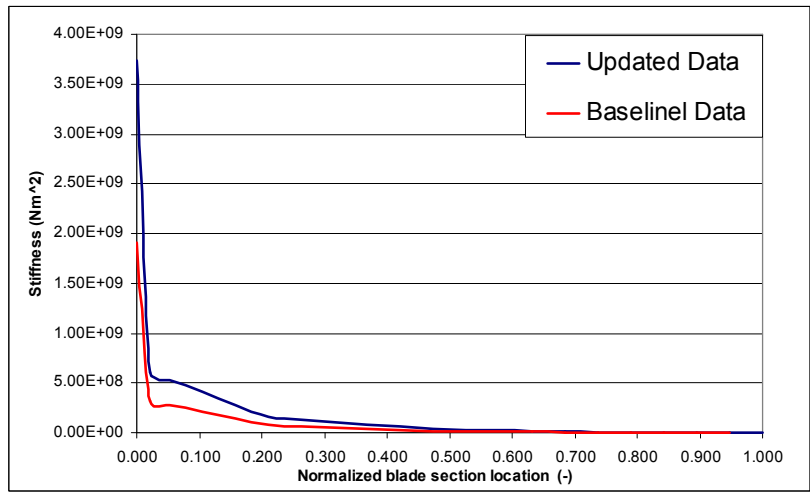

Figure 10: Flap-wise stiffness comparison

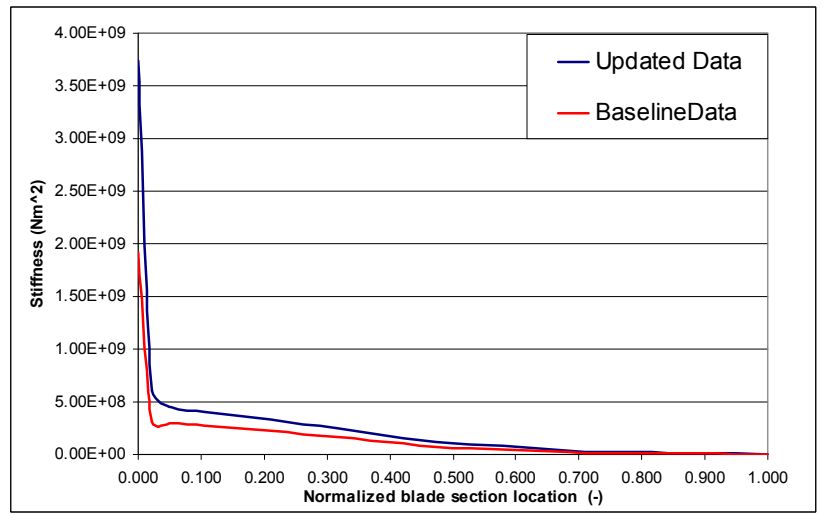

Figure 11: Edge-wise stiffness comparison 
Figures 12-14 compare mode shapes of the baseline and updated blades. Note that the first two flap modes are hardly affected by the model updating; the $1^{\text {st }}$ lag mode, though, is considerably different.

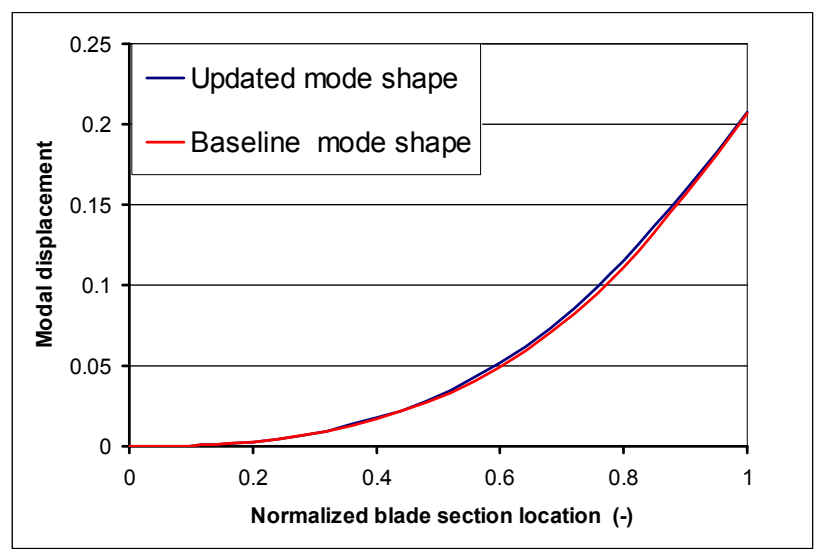

Figure 12: $1^{\text {st }}$ flap mode

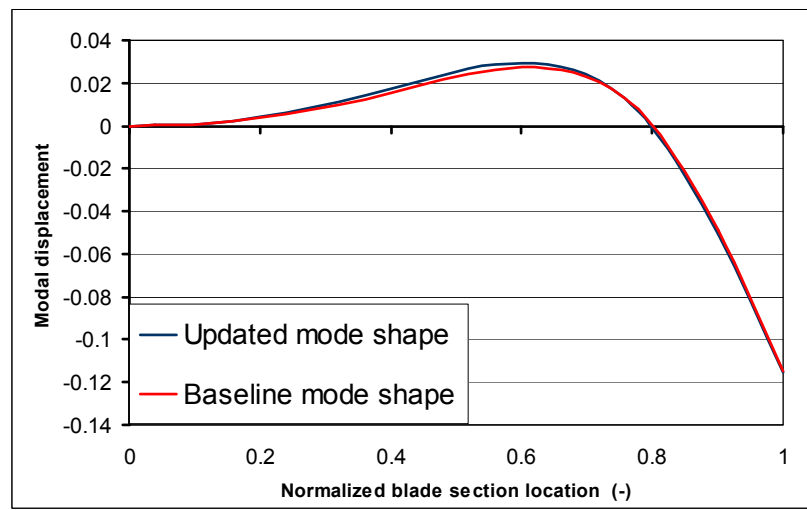

Figure 13: $2^{\text {nd }}$ flap mode

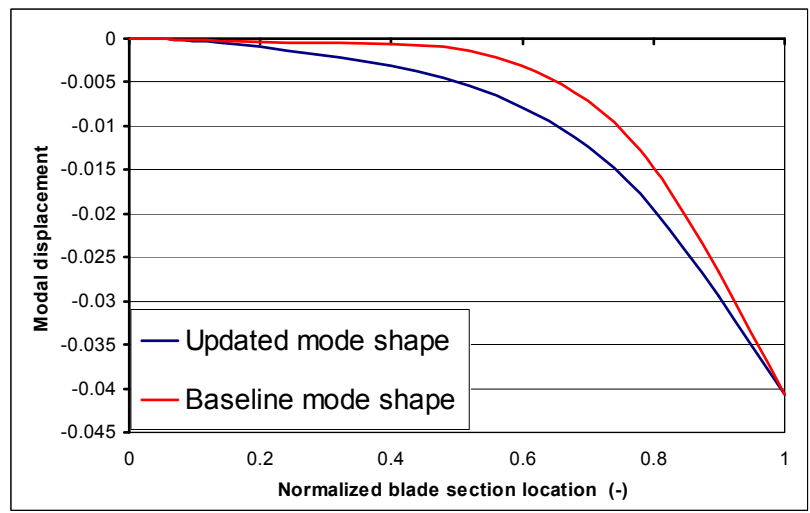

Figure 14: $1^{\text {st }}$ edge mode

Table 7 below shows the concurrence achieved in the frequency response by updating the structural properties of the blade. 
Table 7: Comparison of updated-blade and experimentally determined GRC-blade frequencies

\begin{tabular}{|l|c|c|}
\hline Mode & $\begin{array}{c}\text { Updated } \\
(\mathbf{H z})\end{array}$ & $\begin{array}{c}\text { Experimental } \\
(\mathbf{H z})\end{array}$ \\
\hline 1st Flap & 1.722 & 1.72 \\
\hline 2nd Flap & 2.410 & 2.41 \\
\hline 1st Edge & 4.843 & 4.84 \\
\hline
\end{tabular}

\section{GRC Tower Properties Estimation}

To model the GRC steel tower in FAST, we need its distributed properties and mode shapes. The mode shapes depend on the tower distributed properties and its head mass. We first develop a baseline tower model using tower geometry from Reference 3 and tower head data from Reference 4. Next, using BModes, we compute the baseline-tower modes. Section 3.1 describes the baseline tower and its computed modes. As for the experimental data, time constraint allowed only the $1^{\text {st }}$ side-to-side modal frequency to be measured with a reasonable degree of confidence (Section 3.2). Because only one experimental datum had to be matched, the model updating was trivial; we describe this in Section 3.2. Section 3.3 provides the updated tower model structural properties and its modes, which we again computed using BModes. Section 3.4 compares the distributed and modal properties of the baseline and updated tower models. We use the updated tower properties to model the GRC tower.

\subsection{Baseline Tower Structural Properties and Modes}

For the GRC tower, drawings were available, which we used to compute the inertia and stiffness variation along its length. The drawings provided dimensions such as the tower height and the variation of its diameter and wall thickness along its length. The actual tower cross section is a polygon with 24 faces. For calculation purposes, we approximate it with a circle, i.e., we assume the tower to be tubular with circular cross sections. We divided the tower into 10 equal-length segments and used the drawings to obtain the geometry of the 11 sections bounding these segments. Table 9 lists geometrical properties of these sections.

Table 8: GRC tower dimensions

\begin{tabular}{|c|c|c|c|}
\hline Section & $\begin{array}{c}\text { Distance } \\
\text { from tower } \\
\text { base }\end{array}$ & $\begin{array}{c}\text { Outside } \\
\text { diameter }\end{array}$ & $\begin{array}{c}\text { Wall } \\
\text { thickness }\end{array}$ \\
\hline $\mathbf{( - )}$ & $\mathbf{m}$ & $\mathbf{m}$ & $\mathbf{~}$ \\
\hline $\mathbf{1}$ & 0.000 & 3.026 & 0.019 \\
\hline $\mathbf{2}$ & 5.361 & 2.931 & 0.019 \\
\hline $\mathbf{3}$ & 10.723 & 2.866 & 0.016 \\
\hline $\mathbf{4}$ & 16.084 & 2.853 & 0.016 \\
\hline $\mathbf{5}$ & 21.446 & 2.694 & 0.016 \\
\hline $\mathbf{6}$ & 26.807 & 2.470 & 0.013 \\
\hline $\mathbf{7}$ & 32.169 & 2.278 & 0.013 \\
\hline $\mathbf{8}$ & 37.530 & 2.046 & 0.013 \\
\hline $\mathbf{9}$ & 42.891 & 1.893 & 0.013 \\
\hline $\mathbf{1 0}$ & 48.253 & 1.740 & 0.013 \\
\hline $\mathbf{1 1}$ & 53.614 & 1.646 & 0.013 \\
\hline
\end{tabular}

Table 10 shows the baseline tower structural properties calculated using the tower geometry and material properties. The quantity in the second column, $\mathrm{x}$, is the distance of the section from the tower base normalized with respect to $H$, where $H$ is the hub height (see Figure 15). 
Table 9: Baseline tower structural properties

\begin{tabular}{|c|c|c|c|c|c|c|}
\hline Station & $\mathbf{X}$ & mass & EI & GJ & EA & ly, Iz \\
\hline & $(-)$ & $\mathbf{K g} / \mathbf{m}$ & $\mathbf{N m}^{\wedge} \mathbf{2}$ & $\mathbf{N m}^{\wedge} \mathbf{2}$ & $\mathbf{G N}$ & $\mathbf{K g}-\mathbf{m}$ \\
\hline 1 & 0.000 & $1.404 \mathrm{E}+03$ & $4.206 \mathrm{E}+10$ & $3.235 \mathrm{E}+10$ & $3.721 \mathrm{E}+01$ & $1.586 \mathrm{E}+03$ \\
\hline 2 & 0.098 & $1.359 \mathrm{E}+03$ & $3.820 \mathrm{E}+10$ & $2.938 \mathrm{E}+10$ & $3.604 \mathrm{E}+01$ & $1.441 \mathrm{E}+03$ \\
\hline 3 & 0.196 & $1.109 \mathrm{E}+03$ & $2.985 \mathrm{E}+10$ & $2.296 \mathrm{E}+10$ & $2.939 \mathrm{E}+01$ & $1.126 \mathrm{E}+03$ \\
\hline 4 & 0.293 & $1.104 \mathrm{E}+03$ & $2.945 \mathrm{E}+10$ & $2.265 \mathrm{E}+10$ & $2.926 \mathrm{E}+01$ & $1.111 \mathrm{E}+03$ \\
\hline 5 & 0.391 & $1.042 \mathrm{E}+03$ & $2.476 \mathrm{E}+10$ & $1.905 \mathrm{E}+10$ & $2.762 \mathrm{E}+01$ & $9.340 \mathrm{E}+02$ \\
\hline 6 & 0.489 & $7.647 \mathrm{E}+02$ & $1.530 \mathrm{E}+10$ & $1.177 \mathrm{E}+10$ & $2.027 \mathrm{E}+01$ & $5.772 \mathrm{E}+02$ \\
\hline 7 & 0.587 & $7.051 \mathrm{E}+02$ & $1.200 \mathrm{E}+10$ & $9.227 \mathrm{E}+09$ & $1.869 \mathrm{E}+01$ & $4.524 \mathrm{E}+02$ \\
\hline 8 & 0.685 & $6.328 \mathrm{E}+02$ & $8.670 \mathrm{E}+09$ & $6.669 \mathrm{E}+09$ & $1.678 \mathrm{E}+01$ & $3.270 \mathrm{E}+02$ \\
\hline 9 & 0.783 & $5.852 \mathrm{E}+02$ & $6.857 \mathrm{E}+09$ & $5.275 \mathrm{E}+09$ & $1.551 \mathrm{E}+01$ & $2.586 \mathrm{E}+02$ \\
\hline 10 & 0.880 & $5.377 \mathrm{E}+02$ & $5.319 \mathrm{E}+09$ & $4.092 \mathrm{E}+09$ & $1.426 \mathrm{E}+01$ & $2.006 \mathrm{E}+02$ \\
\hline 11 & 0.978 & $5.083 \mathrm{E}+02$ & $4.493 \mathrm{E}+09$ & $3.456 \mathrm{E}+09$ & $1.348 \mathrm{E}+01$ & $1.695 \mathrm{E}+02$ \\
\hline
\end{tabular}

Next, we needed the tower modes. This, however, required knowledge of the tower-head mass and inertia, which we calculated using the aggregate effect of the tower-head components, i.e., rotor, hub, drivetrain, nacelle, and the electric generator. The document Weights, Dimension \& Transport Guidelines provided the bulk inertia properties and location of these components. Figure 15 shows major tower dimensions and the location of the tower-head center of mass, which lies on the tower axis. The tower length is $53.61 \mathrm{~m}$ and the hub height is $54.81 \mathrm{~m}$. Note that the towerhead center of mass is assumed to lie on the rotor shaft axis, which is $1.2 \mathrm{~m}$ above the tower top. Table 11 shows the aggregate tower-head inertia properties. Ix is towerhead mass moment of inertia about the shaft axis, and Iy and Iz are the moments of inertia about the other two principal axes located at the tower-head center of mass.

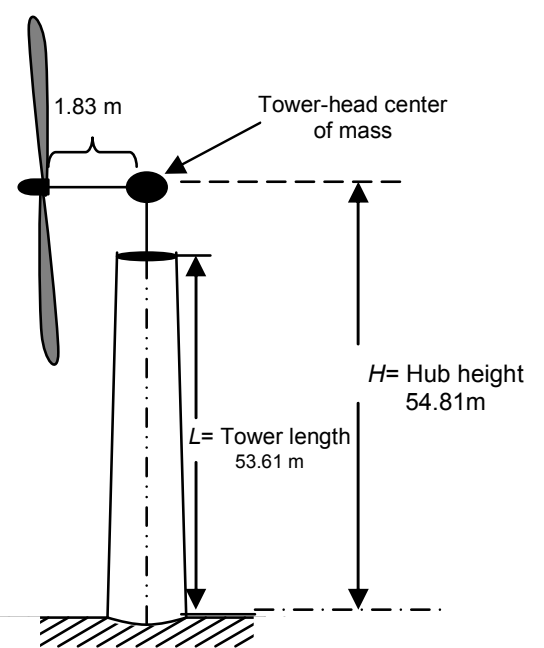

Figure 15: Tower schematic

Table 10: Tower-head properties

\begin{tabular}{|c|c|c|}
\hline Property & \multicolumn{1}{|c|}{ Value } & Units \\
\hline $\mathrm{Ix}$ & $1.313 \mathrm{E}+06$ & $\mathrm{Kg} \mathrm{m}^{\wedge} \mathbf{2}$ \\
\hline $\mathrm{Iy}$ & $7.329 \mathrm{E}+05$ & $\mathrm{Kg} \mathrm{m}^{\wedge} \mathbf{2}$ \\
\hline $\mathrm{Iz}$ & $7.329 \mathrm{E}+05$ & $\mathbf{K g ~ m}^{\wedge} \mathbf{2}$ \\
\hline Total mass & $3.05 \mathrm{E}+04$ & $\mathbf{~ K g}$ \\
\hline
\end{tabular}

Using the baseline tower structural properties, BModes provided the tower mode shapes and corresponding frequencies. Figure 16 shows the first three side-to-side flexural modes and Figure 17 shows the first three fore-aft modes. The $1^{\text {st }}$ side-to-side and the $1^{\text {st }}$ fore-aft modal frequencies are $0.546 \mathrm{~Hz}$ and $0.551 \mathrm{~Hz}$ respectively. These and other frequencies are shown in the two figures. As for the blade, all the tower modes are also mass-normalized. 


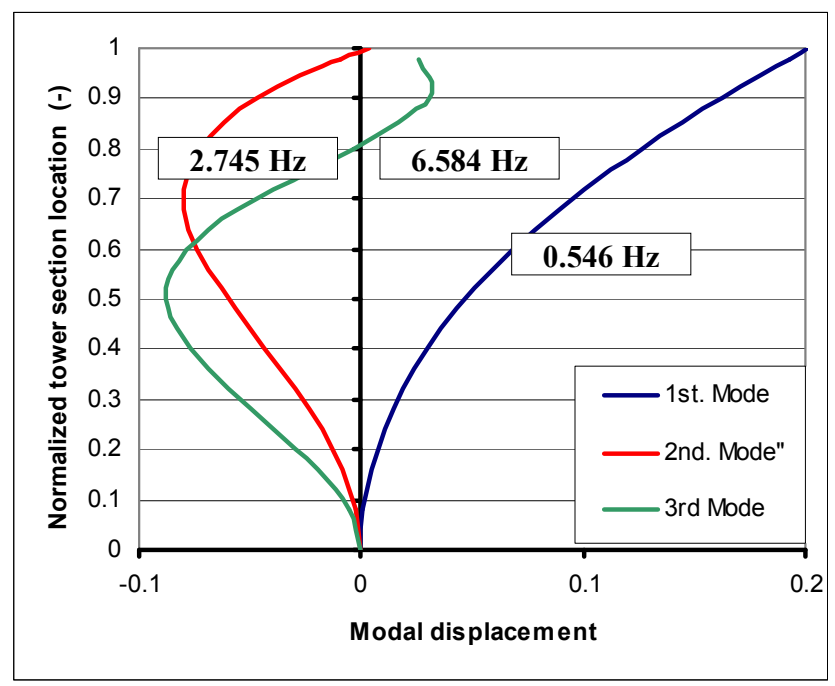

Figure 16: Tower side-to-side mode shapes

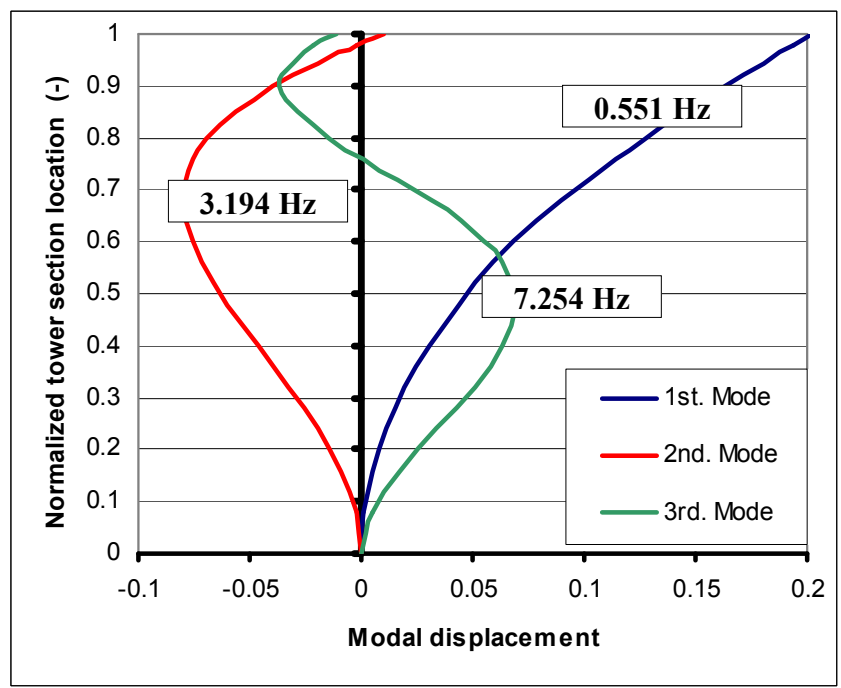

Figure 17: Tower fore-aft mode shapes

\subsection{Experimental Data for the GRC Tower}

A simple experimental test was conducted on the GRC tower. The test engineers attached two uni-axial accelerometers to the nacelle-frame, positioned a significant distance apart and parallel to the shaft axis, so as to pick side-to-side motion at the two points. The intent was to pick sideto-side lateral motion of the tower (by adding the signals from the two accelerometers) and also the twist motion of the tower top (by taking the difference of the two signals). Manual braking was used to excite the tower structure. The braking operation consisted of overriding the blade-tip brakes deployment, allowing the rotor to rotate freely, and applying the mechanical brake to suddenly stop the rotor. This sudden stop induced a sideways excitation of the tower.

Signals from the two accelerometers were post-processed to obtain the frequency responses; these are plotted in Figure 18. The first peak response $(0.467 \mathrm{~Hz})$ from each accelerometer is almost 
identical and corresponds to the $1^{\text {st }}$ side-to-side tower mode. Test engineers did not have enough information to identify modes associated with the other peaks in the plot. The next section describes how we updated our baseline tower to match the $1^{\text {st }}$ side-to-side tower frequency.

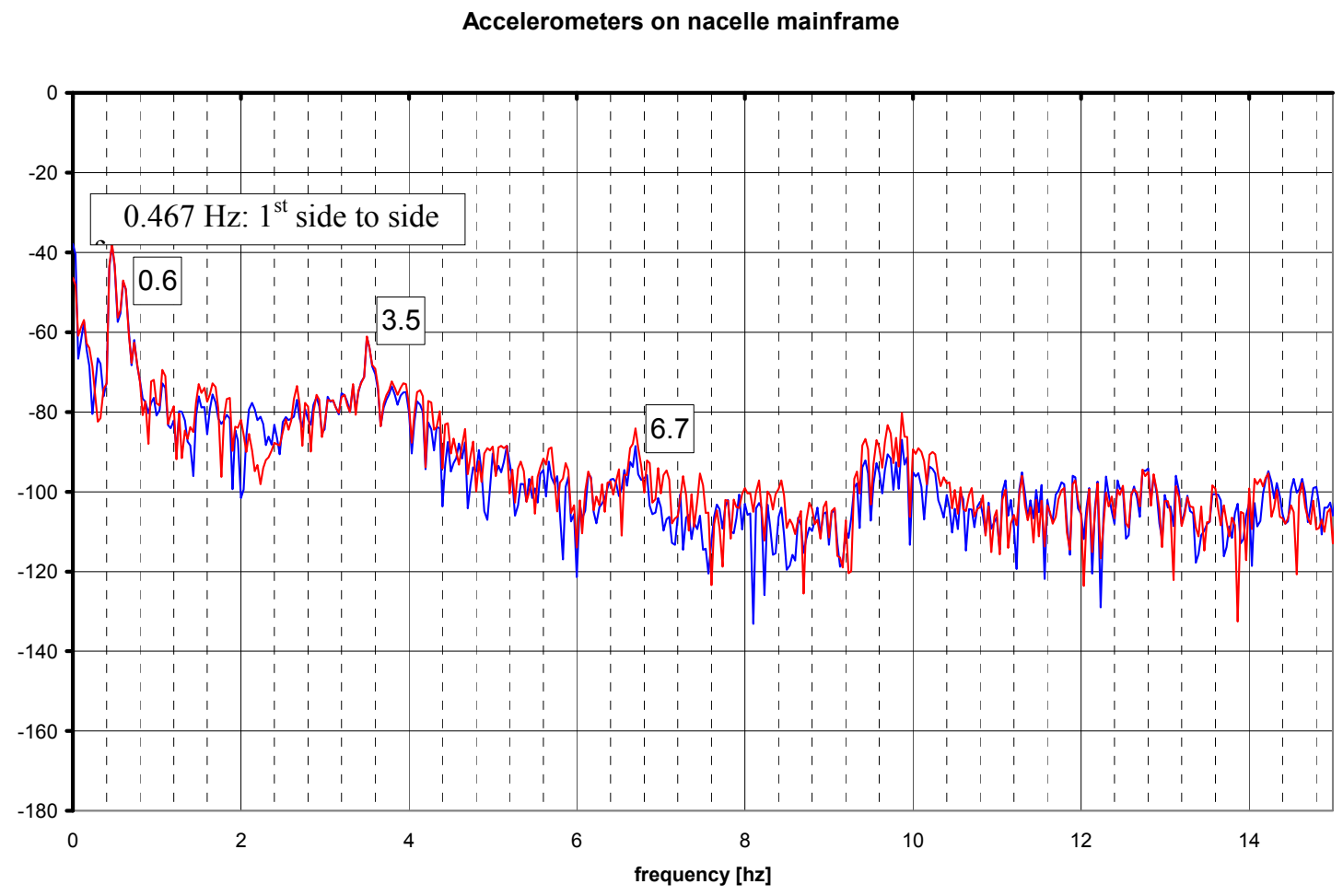

Figure 18: Experimentally determined tower side-to-side sway frequency response

\subsection{Updated Tower Structural Properties}

While we could accord a high level of confidence to the distributed properties of the GRC tower because of its simple geometry and available drawings, we could not do the same for its head inertia or its base attachment to the ground. BModes assumes a perfect cantilevered attachment to the ground, which may not be true because of the foundation flexibility. To uniquely determine the new head inertia and the foundation flexibility, we needed at least two pieces of experimental data; we had only one - the tower $1^{\text {st }}$ side-to-side frequency. We therefore decided to reduce the baseline tower base stiffness to reasonably simulate the elastic foundation and then simply finetune the tower head mass so as to match the tower side-to-side frequency. Following consultation with an engineer with considerable field experience, we reduced the stiffness of the baseline tower base by $20 \%$ (to simulate elastic foundation effect). Then we used BModes iteratively to determine the new head inertia that yielded the same $1^{\text {st }}$ side-to-side tower frequency as the experimental one $(0.467 \mathrm{~Hz})$.

The solid line in Figure 19 shows the updated (arbitrarily modified, strictly speaking) tower flexural stiffness near the tower base region. The dotted line shows variation of the flexural stiffness of the baseline tower. Table 12 compares the head mass inertia properties of the updated and baseline towers. To model the GRC turbine, FAST needs these properties as well as the mode shapes, described in the next section. 


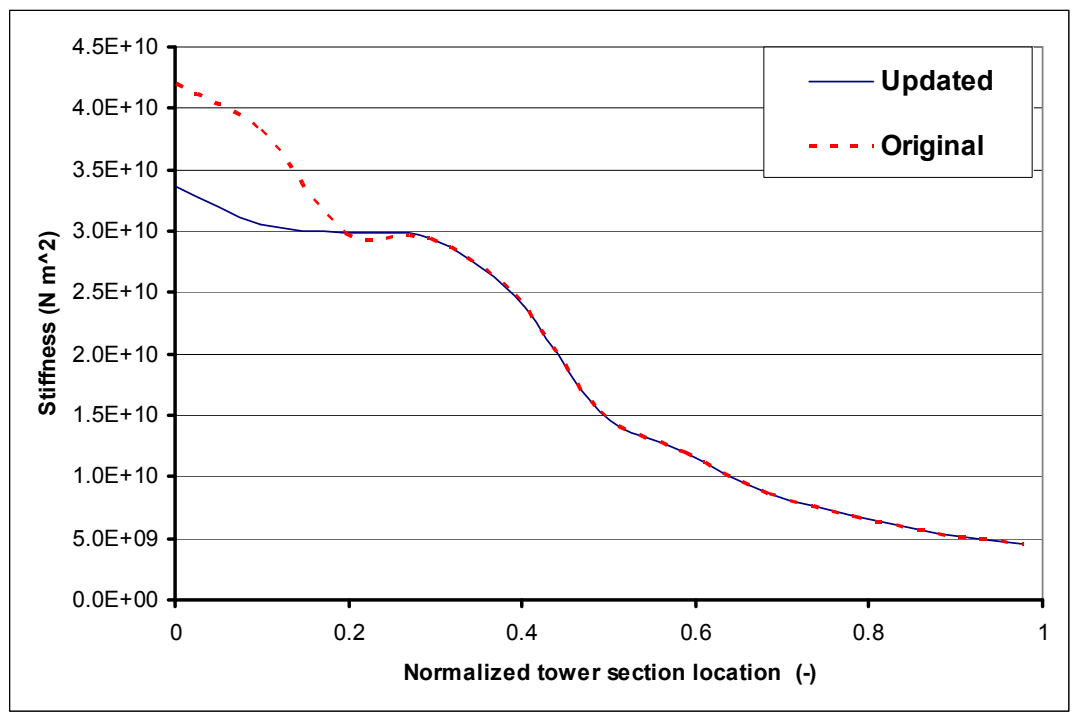

Figure 19: Tower flexural stiffness variation along its length

Table 11: Tower head mass properties

\begin{tabular}{|c|c|c|c|}
\hline \multicolumn{5}{|c|}{ Tower Head Properties } \\
\hline Property & \multicolumn{1}{|c|}{ Original } & \multicolumn{1}{c|}{ Updated } & Units \\
\hline Ix & $1.313 \mathrm{E}+06$ & $1.759 \mathrm{E}+06$ & $\mathrm{Kg} \mathrm{m}^{\wedge} \mathbf{2}$ \\
\hline ly & $7.329 \mathrm{E}+05$ & $9.821 \mathrm{E}+05$ & $\mathrm{Kg} \mathrm{m}^{\wedge} \mathbf{2}$ \\
\hline Iz & $7.329 \mathrm{E}+05$ & $9.821 \mathrm{E}+05$ & $\mathrm{Kg} \mathrm{m}^{\wedge} \mathbf{2}$ \\
\hline mass & $3.05 \mathrm{E}+04$ & $4.087 \mathrm{E}+04$ & $\mathbf{~ K g}$ \\
\hline
\end{tabular}

\subsection{Updated Tower Modes}

Using the tower and tower-head properties, we used BModes to compute the updated tower modes. Table 13 compares frequencies of the first three side-to-side and the first three fore-aft flexural modes for the baseline and the updated tower models. The $1^{\text {st }}$ side-to-side tower mode frequency, shown in red, exactly matches the experimentally measured frequency.

Table 12: Comparison of tower flexural mode frequencies

\begin{tabular}{|c|c|c|c|c|c|}
\hline \multirow{2}{*}{} & \multicolumn{2}{|l|}{ Side to side frequency } & \multicolumn{2}{l|}{ Fore-aft frequency } & \multirow{2}{*}{} \\
\cline { 2 - 5 } & Baseline & Updated & Baseline & Updated & \multirow{2}{*}{} \\
\hline 1st Mode & 0.546 & 0.467 & $5.51 \mathrm{E}-01$ & $4.72 \mathrm{E}-01$ & $\mathrm{~Hz}$ \\
\hline 2nd Mode & 2.745 & 2.454 & $3.19 \mathrm{E}+00$ & $2.91 \mathrm{E}+00$ & $\mathrm{~Hz}$ \\
\hline 3rd Mode & 6.584 & 6.136 & $7.25 \mathrm{E}+00$ & $6.69 \mathrm{E}+00$ & $\mathrm{~Hz}$ \\
\hline
\end{tabular}

Figure 20 shows the first three side-to-side flexural modes of the updated tower and compares these with the baseline tower modes. Figure 21 does the same for the fore-aft tower modes. All the modes are mass-normalized. 


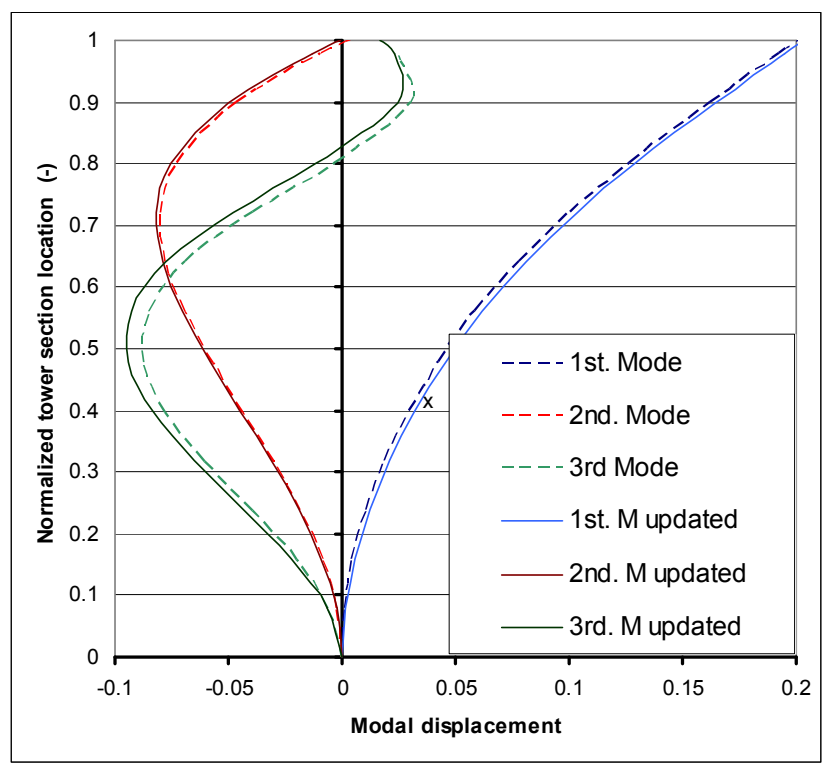

Figure 20: Side-to-side mode shapes comparison

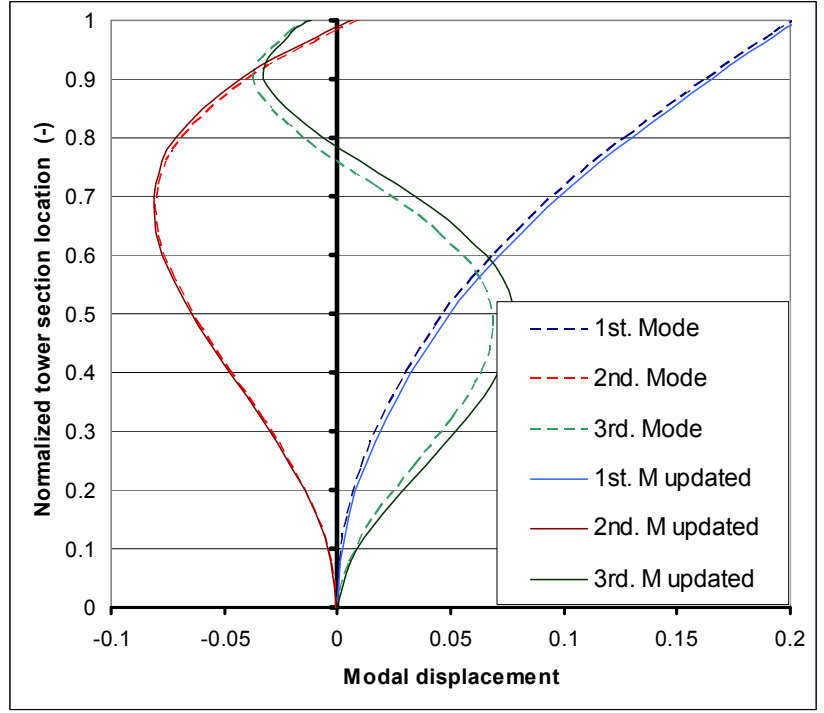

Figure 21: Fore-aft mode shapes comparison

For tower modeling, FAST needs polynomial fits of the first two side-to-side and the first two fore-aft flexural modes (higher flexural and all torsion modes are ignored). Table 14 shows the $6^{\text {th }}$-order polynomial fits of these modes. 
Table 13: Polynomial expressions of the tower modes

\begin{tabular}{|c|c|c|c|c|c|c|}
\hline Mode & $\begin{array}{c}\text { Frequency } \\
\text { (Hz) }\end{array}$ & אינה & -.... & omial & s & $x^{6}$ \\
\hline $1^{\text {st }}$ Side-to-side & 0.4673 & 1.1445 & -0.5231 & 140 & 1.0153 & -0.6507 \\
\hline $1^{\text {st }}$ Fore-aft & 0.4719 & 32 & -0.5406 & 23 & 0.9883 & -0.6462 \\
\hline $2^{\text {nd }}$ Side-to-side & 2.4537 & 32.4280 & -50.2380 & 79.9210 & -90.8900 & 29.7790 \\
\hline $2^{\text {nd }}$ Fore-aft & 2.9071 & 78.7820 & -123.4400 & 192.2600 & -232.9000 & 86.2920 \\
\hline
\end{tabular}

\section{Conclusions and Future Plans}

Using an implicit model updating technique, we developed a finite-element model of the GRC blade model that closely matched the experimental data. Then we determined its modes and distributed structural properties required by FAST. We determined similar data for the GRC tower. Updating the tower model, however, was straightforward because we had to match only one experimental datum, the $1^{\text {st }}$ side-to-side tower frequency.

Compared to the tower test data, we had more data available for the blade. Still, it was not sufficient to allow a more rigorous blade modeling. No experimentally determined mode shapes were available, for example. The lack of additional data, though it made the updating task relatively easier, precluded determination of a better model. A better model, combined with additional test data, would have allowed computation of modal assurance criteria (MACs) and a more refined estimate of the blade-distributed properties. MACs [20] provide a quantitative estimate of the closeness between the measured and analytically computed modes, thereby lending a measurable confidence to the updated model. Considering that FAST uses only a few modes to model the blade, our estimated model was perhaps adequate.

Realizing the frequent need by the industry to estimate distributed structural properties of actual blades and towers, for which reliable test data are rarely available and difficult and expensive to measure, we plan to extend the system identification technique in the future for broader applications. The extended technique will allow for different sets of available data, statistical minimization of noise in the test data, semi-automated computation of weighting functions, and determination of MACs. We will assess sophisticated system identification techniques already available in literature and upgrade these to accommodate features peculiar to wind turbine blades, e.g., coupled modes and gyroscopic effects.

\section{Acknowledgments}

Thanks are due to Sandy Butterfield for motivating this work and to Jeroen Van Dam and Mark Meadors for providing the experimental data essential to this effort. DOE supported this work under contract number DE-AC36-83CH10093.

\section{References}

1. Jonkman, J.M.; Buhl Jr., M.L. (2005). FAST User's Guide, NREL/EL-500-29798. Golden, Colorado: National Renewable Energy Laboratory.

2. Bir, G.S. (2005). User's Guide to BModes; Software for Computing Rotating Beam Coupled Modes, NREL TP-500-38976, Golden, Colorado: National Renewable Energy Laboratory. 
3. Malcolm, D.J.; Hansen, A.C. (August 2002). "WindPact Turbine Rotor Study," NREL/SR-500-32495, National Renewable Energy Laboratory, Golden, Colorado, USA.

4. SimPack Web Site, http://www.simpack.com/websitep.html, accessed 2007.

5. Wei, F-S. (January 1989). "Structural Dynamic Model Modification using Vibration Test Data," $7^{\text {th }}$ International Modal Analysis Conference, Las Vegas, Nevada, January 1989, 562-567.

6. Berman A.; Nagy, E.J. (1983). "Improvement of Large Analytical Model using Test Data,” AIAA Journal, 21(8), 1983, 1168-1173.

7. Caesar, B. (April 1987). "Updating System Matrices using Modal Test Data," $5^{\text {th }}$ International Modal Analysis Conference, London, England, April 1987, 453-459.

8. Minas, C.; Inman, D.J. (1990). "Matching Finite Element Models to Modal Data," Transactions of the ASME, Journal of Vibration and Acoustics, 112(1), 1990, 84-92.

9. Ross, R.G (1971). "Synthesis of Stiffness and Mass Matrices," SAE conference paper 710787.

10. Brauch, M.; Bar-Itzhack, I.Y. (1978). "Optimal Weighted Orthogonalization of Measured Modes,” AIAA Journal, 16(4), 1978, 346-351.

11. Wei, F-S. (1990). "Structural Dynamic Model Improvement using Vibration Test Data," AIAA Journal, 28(9), 1990, 175-177.

12. Zimmerman, D.C.; Widengren, M. (1990). "Correcting Finite Element Models using a Symmetric Eigenstructure Assignment Technique,” AIAA Journal, 28(9), 1990, 16701676.

13. Blakely, K.D.; Walton, W.B., (1984). "Selection of Measurements and Parameter Uncertainties for Finite Element Model Revision," $2^{\text {nd }}$ International Modal Analysis Conference, Orlando, Florida, 1984, 82-84.

14. Flores-Santiago, O.; Link, M. (May 1993). "Localization Techniques for Parametric Updating of Dynamic Mathematical Models," International Forum on Aeroelasticity and Structural Dynamics, Strasbourg, France, May 1993.

15. Link, M. (May 1992). "Requirements of the Structure of the Analytical Models used for Parameter Identification," IUTAM Symposium on Inverse Problems in Engineering Mechanics, Tokyo, Japan, May 1992.

16. Nalitolela, N.G.; Penny J.E.T.; Friswell, M.I. (1992). "A Mass or Stiffness Addition Technique for Structural Parameter Updating," International Journal of Analytical and Experimental Modal Analysis, 7(3), 1992, 157-168.

17. Collins, J.D.; Young, J; Kiefling, L(1972). "Methods and Applications of System Identification in Shock and Vibration," System Identification of Vibrating Structures, 1972 Winter Annual Meeting of the ASME, 1972, 45-71.

18. Collins, J.D.; Hart G.C.; Hassleman, T.K.; Kennedy B. (1974). "Statistical Identification of Structures," AIAA Journal, 12(2), 1974, 185-190.

19. Friswell, M.I. (1989). "The Adjustment of Structural Parameters using a Minimum Variance Estimator," Journal of Mechanical Systems and Signal Processing, 3(2), 1989, 143-155.

20. Allemang, R.J. and Brown D.J., "Correlation Coefficient for Modal Vector Analysis," Proceedings of the International Modal Analysis Conference, IMAC I, 1983, 110-116. 


\section{REPORT DOCUMENTATION PAGE}

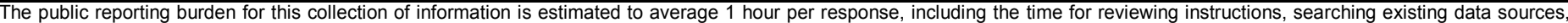

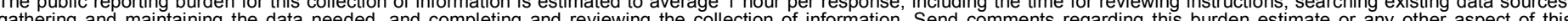

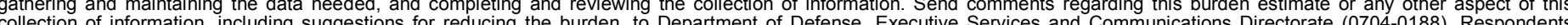

should be aware that notwithstanding any other provision of law, no pe

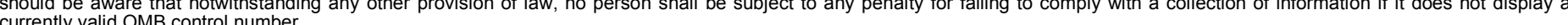

PLEASE DO NOT RETURN YOUR FORM TO THE ABOVE ORGANIZATION.

\begin{tabular}{l|l|l|l} 
1. REPORT DATE $(D D-M M-Y Y Y Y)$ & 2. & REPORT TYPE & 3. DATES COVERED (FrOm - TO)
\end{tabular}

November 2007

Technical paper

4. TITLE AND SUBTITLE

Estimation of Blade and Tower Properties for the Gearbox Research

Collaborative Wind Turbine 5a. CONTRACT NUMBER

DE-AC36-99-G010337

5b. GRANT NUMBER

5c. PROGRAM ELEMENT NUMBER

5d. PROJECT NUMBER

NREL/TP-500-42250

5e. TASK NUMBER

WER8.2001

5f. WORK UNIT NUMBER
7. PERFORMING ORGANIZATION NAME(S) AND ADDRESS(ES)

National Renewable Energy Laboratory

1617 Cole Blvd.

Golden, CO 80401-3393
8. PERFORMING ORGANIZATION REPORT NUMBER

NREL/TP-500-42250

9. SPONSORING/MONITORING AGENCY NAME(S) AND ADDRESS(ES)

10. SPONSOR/MONITOR'S ACRONYM(S) NREL

11. SPONSORING/MONITORING AGENCY REPORT NUMBER

12. DISTRIBUTION AVAILABILITY STATEMENT

National Technical Information Service

U.S. Department of Commerce

5285 Port Royal Road

Springfield, VA 22161

13. SUPPLEMENTARY NOTES

14. ABSTRACT (Maximum 200 Words)

This report documents the structural and modal properties of the blade and tower of a 3-bladed 750-kW upwind

turbine to develop an aeroelastic model of the wind turbine.

15. SUBJECT TERMS

wind energy; wind turbine; wind turbine modeling; Gearbox Reliability Collaborative

\begin{tabular}{l}
\hline \multicolumn{3}{|l|}{ 16. SECURITY CLASSIFICATION OF: } \\
\hline \begin{tabular}{l|l|l|} 
a. REPORT & b. ABSTRACT & c. THIS PAGE \\
Unclassified & Unclassified & Unclassified \\
& & \\
\hline
\end{tabular} \\
\hline
\end{tabular}

\begin{tabular}{|c|c|} 
17. LIMITATION & 18. \\
OF ABSTRACT & OF PAGES \\
UL &
\end{tabular}

19a. NAME OF RESPONSIBLE PERSON

19b. TELEPHONE NUMBER (Include area code) 